\title{
HTGR $=88179$
}

Ro: $2 \%$

\section{PROJEC CONTROL DOCUMENT APPROVAL SUMMARY}

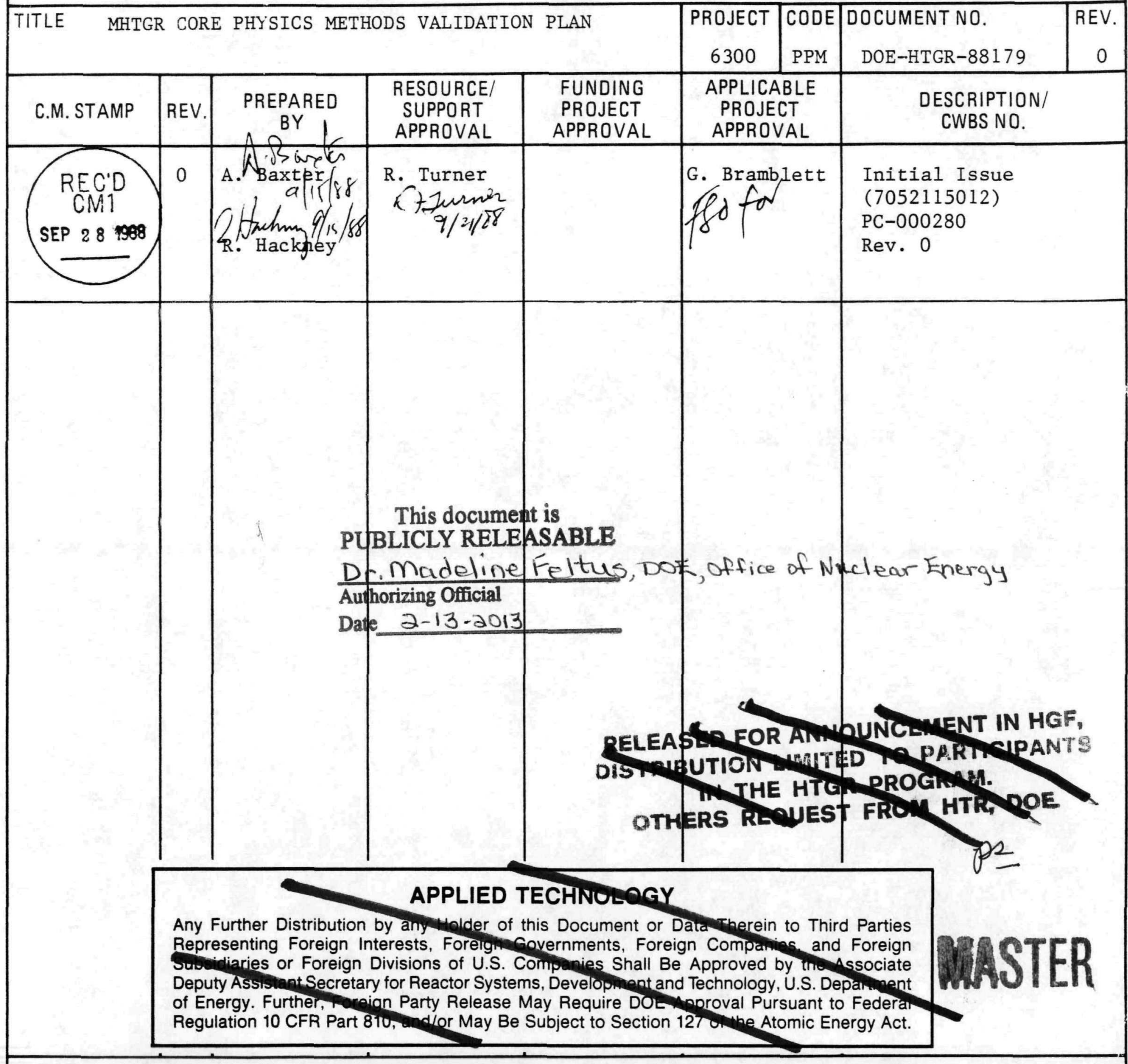

GAPROPRIETARY INFORMATION

THIS DOCUMENT IS THE PROPERTY OF GA TECHNOLOGIES INC. ANY TRANSMITTAL OF THIS DOCUMENT OUTSIDE GA WILL BE IN CONFIDENCE. EXCEPT WITH THE WRITTEN CONSENT OF GA, (1) THIS DOCUMENT MAY NOT BE COPIED IN WHOLE OR IN PART AND WILL BE RETURNED UPON REQUEST OR WHEN NO LONGER NEEDED BY RECIPIENT AND (2) INFORMATION CONTAINED HEREIN MAY NOT BE COMMUNICATED TO OTHERS AND MAY BE USED BY RECIPIENT ONLY FOR THE PURPOSE FOR WHICH IT WAS TRANSMITTED. 


\section{DISCLAIMER}

This report was prepared as an account of work sponsored by an agency of the United States Government. Neither the United States Government nor any agency Thereof, nor any of their employees, makes any warranty, express or implied, or assumes any legal liability or responsibility for the accuracy, completeness, or usefulness of any information, apparatus, product, or process disclosed, or represents that its use would not infringe privately owned rights. Reference herein to any specific commercial product, process, or service by trade name, trademark, manufacturer, or otherwise does not necessarily constitute or imply its endorsement, recommendation, or favoring by the United States Government or any agency thereof. The views and opinions of authors expressed herein do not necessarily state or reflect those of the United States Government or any agency thereof. 


\section{DISCLAIMER}

Portions of this document may be illegible in electronic image products. Images are produced from the best available original document. 


\section{IIST OF EFFECTIVE PAGES}

\section{Page Number}

i through ix

1-1 through $1-10$

2-1 through 2-13

3-1 through $3-9$

4-1 through 4-19

5-1 through 5-11

6-1 through 6-4

A-1 through A-21

Total Pages
Page Count

Revision

9

10

13

9

19

11

4

$\underline{21}$

96
0

0

0

0

0

0

0

\section{DISCLAMMER}

This report was prepared as an account of work sponsored by an agency of the United States Government. Neither the United States Government nor any agency thereof, nor any of their employees, makes any warranty, express or implied, or assumes any legal liability or responsibility for the accuracy, completeness, or usefulness of any information, apparatus, product, or process disclosed, or represents that its use would not infringe privately owned rights. Reference herein to any specific commercial product, process, or service by trade name, trademark, manufacturer, or otherwise does not necessarily constitute or imply its endorsement, recommendation, or favoring by the United States Government or any agency thereof. The views and opinions of authors expressed herein do not necessarily state or reflect those of the United States Government or any agency thereof. 
LIST OF ACRONYMS . . . . . . . . . . . . . . . . . . . . vi vi SUMMARY ............................. viii

1. INTRODUCTION .................... 1- . .

1.1. Report Overview .................. 1-1

1.1.1. Purpose and Organization .......... 1-1

1.1.2. Background ............... 1-2

1.2. Overview of Core Physics Methods............ 1-3

1.3. Strategy . . . . . . . . . . . . . . 1-6

1.3.1. Reanalysis of Previous Validation Studies . . 1-8

1.3.2. Documentation of Previous Validation Studies . - 1-8

1.3.3. Comparison of New Experimental Data to Calculation ............. . 1-8

1.3.4. Comparison of Other (Non-GA) Calculations to GA Calculations . . . . . . . . . . 1-10

1.3.5. Verification............... 1-10

2. VERIFICATION AND VAIIDATION REQUIREMENTS . . . . . . . . . 2-1

2.1. Required Accuracies for Computational Methods .... 2-1

2.2. Verification and Validation Criteria........ 2-8

2.2.1. Industry Standards ............ 2-8

2.2.2. Regulatory Guidance ............ 2-9

2.2.3. Definitions, Requirements, and Guidelines

Selected for Verification and Validation... 2-10

2.3. Control of Verified and Validated Computational

Methods .................. 2-13

3. DESCRIPTION OF DESICN METHODS ............ 3-1

3.1. Design Code Input Data Processing .......... 3-1

3.2. Design Code Description ............ 3-3

3.3. Design Parameters .. . . . . . . . . . 3-5

3.3.1. Temperature Coefficient ......... 3-5

3.3.2. Control Rod (and Other Material) Reactivity.
Worth . . . . . . . . . 3-7 
3.3.3. Core Neutron Flux and Power Distribution ... 3-7

3.3.4. Decay Heat Production ......... 3-7

4. VERIFICATION AND VALIDATION OF DESIGN METHODS . . . . . . 4-1

4.1. Temperature Coefficient ............ 4-3

4.1.1. Validation Status ............ 4-3

4.1.2. Validarion Plan ............. 4-4

4.2. Control Rod Reactivity Worth . . . . . . . . . 4-8

4.2.1. Validation Status .......... 4-8

4.2.2. Valdation plan............. 4-9

4.3. Core Neutron Flux and Power Distributions ...... 4-11

4.3.1. Validation Status ........... 4-11

4.3.2. Validation Plan ............ 4-12

4.4. Core Criticality and Material Reactivity Worth . . . 4-12

4.4.1. Validation status ........... 4-13

4.4.2. Validation Plan ........... 4-13

4.5. Water Ingress Effects .............. 4-14

4.5.1. Validation Status ........... 4-14

4.5.2. Validation Plan ........... 4-14

4.6. Decay hegt Production ........... 4-16

4.6.1. Validation Status ........... 4-16

4.6.2. Validation Plas .......... 4-16

4.7. Code Verlfication ............. 4-16

5. SCHEDULE AND COST ESTIMATES ............. 5-1

6. REFERENCES ................ 6- 6 . .

APPENDIX A: TEST FACILITIES AND EXPERIMENTS . . . . . . . . . A-1

FIGURES

1-1. Core physics design sequence . . . . . . . . . . . 1-5

2-1. Method validation flow diagram . . . . . . . . . 2-6

2-2. Illustration of validation procedure for reactor physics methods ...................... 2-7

3-1. Temperature coefficient calculational methods . . . . . 3-6

3-2. Control rod reactivity worth calculational methods . . . . 3-8

3-3. Core neutron flux/power distribution calculational methods ..................... 3-9 
5-1. Overall physics validation and verification schedule... . 5-2

5-2. Temperature coefficient methods validation schedule . . . 5-3

5-3. Control rod and reactivity worth methods validation schedule.................... 5-4

5-4. Core neutron flux and power distributions methods validation schedule ............. 5-5

5-5. Core criticality and material reactivity worth methods validation schedule . . . . . . . . . . . . 5-6

5-6. Water ingress reactivity worth methods validation schedule ......... . . . . . . . . . . 5-7

5-7. Decay heat production methods validation schedule .... 5-8

\section{TABLES}

2-1. Core physics technical requirements ........... 2-3

2-2. Core physics assumptions .............. 2-4

2-3. Steps for methods validation ............. 2-5

2-4. Definitions, requirements, and guidelines for verification and validation of computational methods utilized in MHTGR assessments ................. 2-11

4-1. Experimental data and applicability to validation program ................... 4 4-2

4-2. List of physics computer codes used for MHTGR analysis . . 4-17

5-1. Cost sumary for validation program . . . . . . . . . 5-9

5-2. Cost breakdown for validation program ......... 5-10 
$\triangle C-000280 / 0$

\section{LIST OF ACRONYMS}

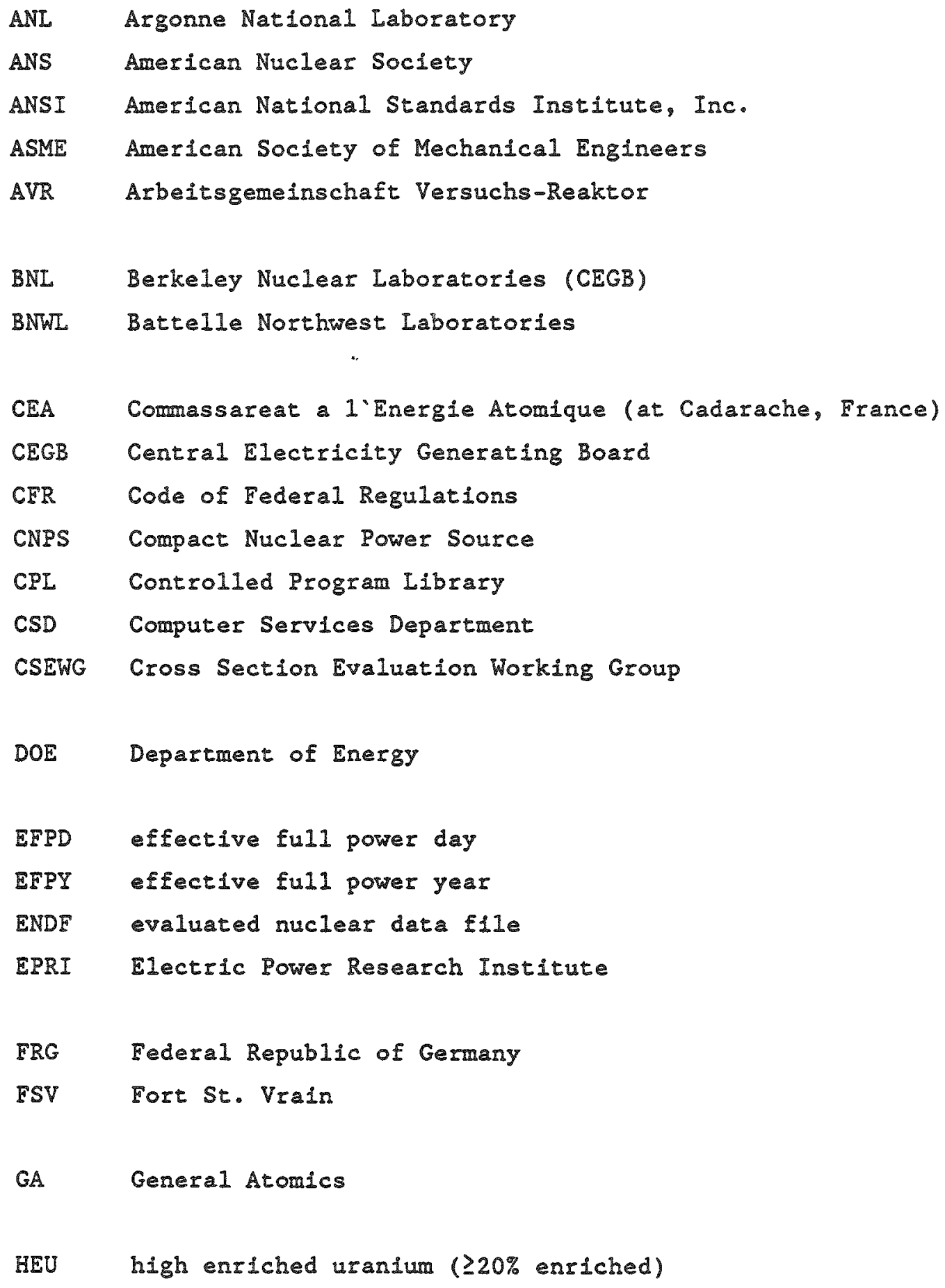




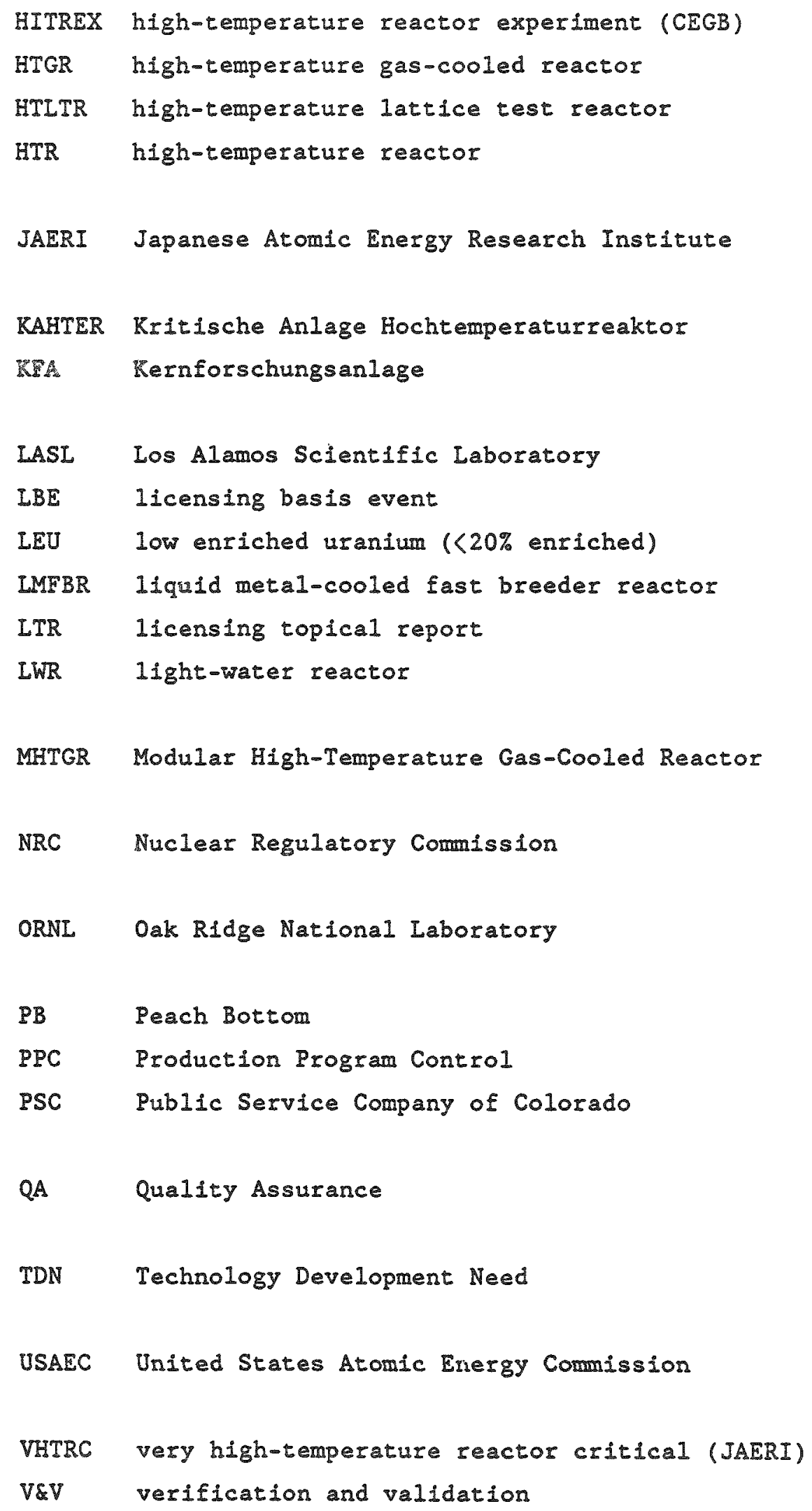


This document contains the verification and validation (V\&V) plan for analytical methods utilized in the nuclear design for normal and off-normal conditions within the Modular High-Temperature Gas-Cooled Reactor (MHTGR). Regulations, regulatory guides, and industry standards have been reviewed and the approach for V\&V has been developed. MHTGR core physics methods are described and the status of previous $V \& V$ is sumarized within this document. Additional work required to verify and validate these methods is identified.

The additional validation work includes comparison of calculations with available experimental data, benchmark comparisons with other validated codes, results from a cooperative program now underway at the Arbeitsgemeinschaft Versuchs-Reaktor GmbH (AVR) facility in Germany, results from a planned series of experiments on the Compact Nuclear Power Source (CNPS) facility at Los Alamos, and detailed documentation of all V\&V studies. In addition, information will be obtained from planned international cooperative agreements to provide supplemental data for V\&V. The regulatory technology development plan will be revised to include these additional experiments.

A thorough review of the verification work already completed for each code will be performed to ensure that they are mathematically correct, well-documented, and well-structured so as to meet program requirements. Verification will be reviewed during the validation effort to be sure completeness. Documentation of this work will be utilized as input for a licensing topical report (LTR) submittal to the Nuclear Regulatory Commission (NRC) Os physics methods. 
A work schedule and cost estimate for completing this plan is also provided. This work schedule indicates the timeframe in which major milestones must be performed in order to complete V\&V tasks prlor to the issuance of preliminary design approval from the NRC. The cost to complete V\&V tasks for core physics computational methods is estimated to be $\$ 2.2 \mathrm{M}$. 


\section{INTRODUCTION}

\subsection{REPORT OVERVIEW}

\subsubsection{Purpose and Organization}

The purpose of this report is to present the V\&V plan for the computational wethods ufilized in the core physics design (Refs. I and 2) of the MHTGR plant. This plan briefly describes each method, sumarizes the V\&V status, identifies the work reeded for V\&V, and defines schedules and costs for completing the work.

Background information and a brief overview of the MHTGR core physics methods is provided in the first section, along with the proposed strategy for the V\&V plan. Next the requirements that the validation plan must meet are described in section 2. This includes the accuracy required of the computational methods, which defines the extent of the validation effort; and the standards and criteria which the plan must follow both in execution and documentation.

Section 3 provides a detailed description of the specific core physics methods which are to be covered by this plan, and discusses each of the computer codes used in these analyses. For each design method, Section 4 describes its current status, the data base available for validation, and the specific plan for validation. The proposed schedule and costs for the overall V\&V plan are given in Section 5; and document references are provided in Section 6. Finally, a description of the test facilities from which experimental data for the validation program may be obtained is given in Appendix A. 


\subsubsection{Background}

The conceptual design of the MHTGR is engineered in a "top-down," goal-oriented manner using the Department of Energy (DOE)-sponsored Integrated Approach.

The Integrated Approach is a systems engineering technique for establishing and defending a well-developed nuclear plant design. The overall objective is safe, economical power production (Goal 0 ). The four goals which support this objective are:

- Maintair plant operation (Goal 1).

- Maintain plant protection (Goal 2).

- Maintair control of radionuclide release (Goal 3).

- Maintain emergency preparedness (Goal 4).

Goal 1 deals with scheduled operations such as energy production, plant shutdown for scheduled maintenance, in-service inspection, etc. Goal 2 deals with unscheduled events in which the plant downtime can impact the plant availability/investment protection. Goal 3 deals with unscheduled events which may involve radionuclide release and, hence, may impact the public's health and safety. Goal 4 deals with emergency preparedness and procedures for public protection in the event of an accident.

The conceptual design of the MHTGR is presented in Ref. 3. The adequacy of this design was assessed against the four goals utilizing quantitative criteria. Assumptions were made regarding the physical models and numerical methods used, and accuracy of the computational methods for the design process. These assumptions must be verified and validated. Industry and regulatory guidelines for $V \& V$ of computational methods have been reviewed to select a V\&V procedure for demonstrating that the analytical methods meet the predictive accuracies assumed by the MHTGR progran. 
This document contains the V\&V plan for the analytical methods utilized to evaluate the core physics under normal operation and off-normal conditions in an MHTGR plant. For purposes of this plan, verffication is defined as:

- Assurance that the operations specified in a numerical model are correctly performed (i.e., demonstrates substantially identical results when compared to known solutions).

and validation is defined as:

- Assurance that the computational method is a correct representation of the process or system for which it is intended (i.e., demonstrates that a verified method adequately correlates with experimental data, reactor operating data, etc.).

\subsection{OVERVIEW OF CORE PHYSICS METHODS}

In principle, the physics design of the MHTGR core can be exactly assessed by solving the general equations of particle transport to calculate the detailed space and energy dependence of the neutron population as a function of time. This is a formidable undertaking, the energy range alone covers seven orders of magnitude, and in practice this solution is approximated using a sequence of design codes which are based on reasonable simplifications to the general transport equations. This, in turn, leads to the need to validate these simplified models.

Because of the nature of the problem, these design codes have been specialized, and groups of codes are used to calculate parameters of interest. For example, a single code, MICROX, is used to determine neutron cross sections averaged over broad energy groups. This code is then used as part of the design sequence to calculate static power distributions in the core, in a separate sequence to determine core temperature coefficients, and in yet another sequence to calculate core shutdown margins. These parameters are the items of interest in the physics 
design and are the variables which are measurable both in the core itself and in validating experiments. Thus, validation is performed on these design methods or code sequences, while verification is carried out on the individual codes themselves.

The current core physics design methods sequence is shown in Fis. 1-1 along with the computer codes used for each method. (Each of these codes is described in Section 3.2.) The codes associated with Box 1 form a group used to process the basic cross section data into a form suitable for the preparation of multigroup cross section sets. The codes (primarily MICROX) associated with Box 2 of Fig. $1-1$ are used to prepare input for the core physics design codes, including multigroup cross section sets averaged over appropriate fine-group spectra. This represents the starting point for most core physics design work.

The static codes are then used to obtain the more detailed and accurate solutions to the physics problems of reactor design (Box 3 of Fig. 1-1). Diffusion theory and/or transport theory codes are used to obtain the system multiplication factor, the neutron flux in each energy group, reaction rates at each space point in the problem and power distribution. The diffusion theory codes are used for problems where the diffusion approximation is valid. This encompasses a wide range of problems for reactors, Including the determination of the overall flux distribution, the effects of fuel zoning, reactivity predictions, and many others. Design problems for which the transport theory codes are generally used include determination of flux disadvantage factors or boundary conditions for control rods or burnable poisons, the reactivity worth of control rods, and other problems involving anisotropic scattering or strong neutron absorption or leakage.

The depletion codes (Box 4 of Fig. 1-1) follow the changing inventories of fuel, fertile materials, burnable poisons, and fission products throughout the operating life of a reactor. These codes have been used for very complex fuel cycles in many high-temperature gas-cooled reactor (HTGR) applications. Because of the many variables involved, 
PC $-000280 / 0$

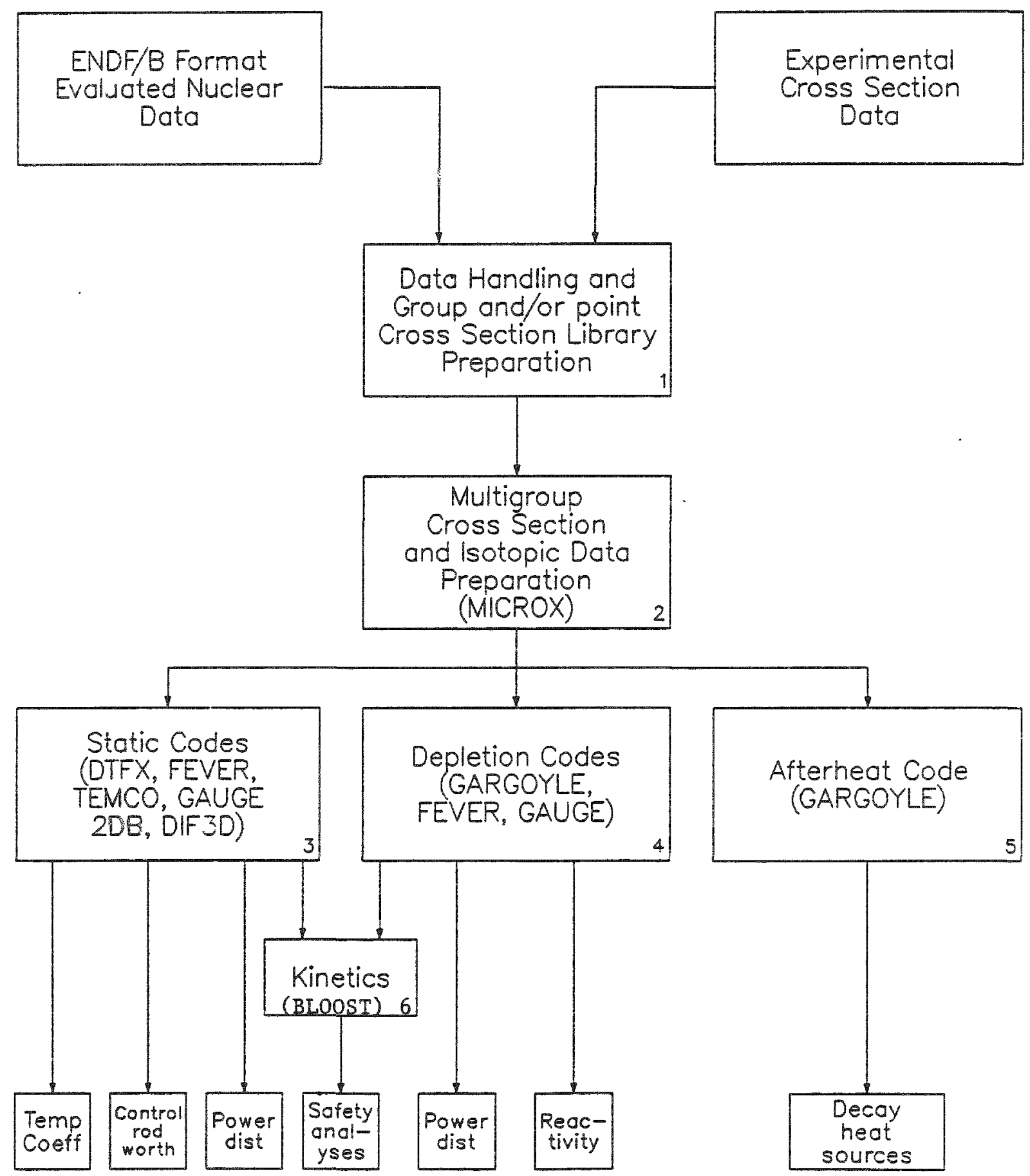

Fig. 1-1. Core physics design sequence 
such as power density, reload frequency, excess reactivity requirements, and varying reload patterns, even the simplest depletion problem may require solutions at many points in time and position. An additional important aspect of the fuel depletion analysis is that of finding a fuel and fertile material loading arrangement that will maintain a stable specified power density profile throughout life.

The afterheat code (Box 5 of Fig. 1-1) is used to calculate the decay heat production as a function of time after reactor shutdown.

The neutron kinetics code, BLOOST (BOx 6 of Fig. 1-1), is used to predict the time-dependent behavior of the neutron flus and associated changes in core power density and temperature during operating transient and reactivity accidents.

As shom in Fig. 1-1, combinations of these static and depletion codes form the core physics design methods (described in section 3) which are used to calculate the parameters of interest such as power distributions, control rod reactivity worths, temperature coefficients, decay heat levels, etc.

\subsection{STRATEGY}

This plan has been developed to ensure that the analytical methods for core physics calculations used in MHTGR analyses are adequate for meeting program technical requirements for licensing. The plan utilizes V\&V activities suggested by industry and regulators to demonstrate that computational method results satisfy accuracy assumptions associated w1th MHTGR program requirements. Results from tasks identified within this document will verify that the operations specified within each model are correctly performed and will validate that the models within each method are correct representations of the process for which they are intended. 
The strategy to be followed is to ensure that the individual codes are verified, and to validate the core physics methods to ensure that these computational methods are adequate for predicting those physics parameters which directy affect safety-related requirements during norma operation and during licensing basis events (LBEs) (i.e., temperature coeficicient, shutdown margin, etc.). The adequacy of these methods will be ensured by validation of the computational methods by comparison of the computed parameters to those obtained from experiments (i.e., control rod reactivity worth measurements, etc.). These calculational methods will involve the use of groups of verified computer codes, as described above.

It should be emphasized that the core physics methods used for the MHTGR conceptual design are basically sound and have previously been validated for high enriched uranium (HEU) fuel cycles. (The documentation of these studies which are applicable to the current program will be updated to meet current V\&V definitions.) The current validation plan was prompted primarily by the change from an HEU to a low enriched uranium (LEU) Fuel cycle. The validation will be performed using one or more of the procedures listed below, with the primary emphasis on the first two procedures.

- Reanalysis of selected previous validation studies.

- Documentation of previous validation studies.

- Comparison of new and/or proposed experimental data with calculations to supplement previous analyses.

- Comparison of other non-General Atomics (GA) calculations with GA calculations.

These four procedures are described in the following sections. 


\subsubsection{Reanalysis of Previous Validation Studies}

This procedure includes reanalysis of selected previous core physics methods validation studies applicable to the current program, i.e., Peach Bottom (PB) and HTGR criticals, PB and Fort St. Vrain (FSV) reactor operation, and the HTLTR experiments, using current methods and reference neutron cross sections. Selected calculations will be repeated using the latest evaluated nuclear data file (ENDF)/B cross sections for comparison. These analyses will be compared to the previous results, and the comparison will be used as a basis for the validity of the previous studies. Documentation will be done consistent with GA procedures, NRC regulations, and industrial standards.

\subsubsection{Documentation of Previous Validation Studies}

Previous undocumented and/or limited documented validation studies will be documented consistent with GA procedures, NRC regulations, and industry standards.

\subsubsection{Comparison of New Experimental Data to Calculation}

Available experimental data which are relevant to the MHTGR physics design will be compared to calculations, and adequately documented. These data include measured core physics data not previously analyzed using GA methods. Physics parameters will be calculated using current GA reference neutron cross sections and methods. For selected data sets, a second calculation, using the latest ENDF/B cross section set, will be done for comparison. The calculated and measured data will be compared, and the data and analyses will be documented consistent with GA procedures, NRC regulations, and industrial standards.

Supplemental new data will be obtained through a cooperative exchange program between the United States DOE and the Federal Republic of Germany (FRG) BMFT (Bundesministerium fur Technik) (Refs. 4 and 5). 
This exchange program will provide results of measurements made on the high-temperature, graphite-moderated, gas-cooled AVR, which can then be compared to calculations made with MHTGR physics design codes. In addition, a similar cooperative program with the Japanese Atomic Energy Research Institute (JAERI) is being planned to obtain validetion data from the JAERI very high-temperature reactor critigal (VHTRC) experiment.

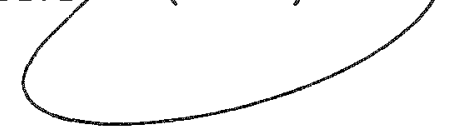

These cooperative programs will supplement the core nuclear data base used in the preliminary design and licensing submittals.

Also, a plan is being prepared to utilize

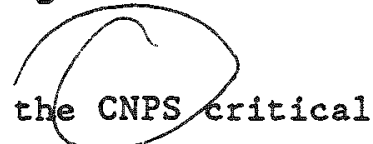
facility at the Los Alamos Scientific Laboratories (LASL) to obtain MHTGR core physics data for the validation program. These planned experiments will provide validation of GA's physics methods for criticality, temperature coefficient, and reflector control rod reactivity worth in a system using MHTGR IEU fuel.

For purposes of this validation program, it is assumed that the cooperative exchange prograns with FRG and JAERI, and the extension of the CNPS critical facility program, have all been approved and test data will be available.

These cooperative programs and the CNPS program consist of two parts:

- Obtain measured core physics data from the AVR test program and from the VHTRC and CNPS critical experiments.

- Calculate these physics parameters using GA methods and compare to the measured data, document the comparisons consistent with GA procedures, NRC regulations, and industry standards. 


\subsubsection{Comparison of Other (Non-GA) Calculations to GA Calculations}

GA calculations of important physics parameters will be compared to the results calculated by other technical organizations. These comparisons may include:

- GA calculations versus FRG calculations of AVR parameters.

- GA caleulations versus Oak Ridge National Laboratory (ORNL) calculations.

- GA calculations versus JAERI calculations.

\subsubsection{Verification}

Marny of the core physics codes have been in use at GA for 25 or more years. During this time, numerous changes, refinements, and modifications have been made, but the basic theory is unchanged. These codes were verified when they were written; and as each change, refinement, and modification was made, the updated code was also verified. This verification included ensuring adequate code documentation; and reviewing the programing structure and format for completeness, correctress, and consistency. Test problems were also run to ensure that the code did Indeed perform the calculations for which it was designed.

To protect these verified computer programs and related data, an automated Archive/Firemaster System has been developed to facilitate the storage, protection, and retrieval of the programs. Calculations are, of course, performed using a code version in this archive system.

The strategy for verification for this program will be to review the verification documentation for the codes used in the physics calculations to ensure that it meets current requirements, and update the verification of individual codes if necessary. These requirements are discussed in Section 2 and sumarized in Table 2-4. 


\section{VERIFICATION AND VAIIDATION REQUIREMENTS}

Analytical methods are utilized in plant-level assessments to demonstrate that the plant meets the top-level criteria. Therefore, it is necessary to ensure the accuracy of the physical models and numerical methods of these analytical tools. Assumptions defining the presumed accuracies of the analytical methods are given in Section 2.1. The V\&V definitions, requirements, and guidelines which will be utilized to verify and validate these assumptions are given in section 2.2. Control of verified and validated versions of the analytical methods are discussed in Section 2.3 .

\subsection{REQUIRED ACCURACIES FOR COMPUTATIONAL METHODS}

Section 1 described the Integrated Approach utilized in developing the MHTGR. A cornerstone of the Integrated Approach is functional analysis, which is a method utilized to develop the bases and justification for plant design selections which support an overall goal. In the process of performing functional analysis, it is frequently necessary to make assumptions concerning the design selections chosen to satisfy the design requirements. In some cases, the assumptions simply anticipate the expected results of a future trade study or analysis. In this case, the assumptions are reviewed after the trade study or analysis has been completed.

In other cases, the assumptions are related to the uncertainties in the design parameters as a result of uncertainties in the computational models and methods. In this case, it is necessary to ensure that the uncertainties in the models and methods do not exceed those uncertainties assumed in the analyses. In order to do this, the computational models and methods must be adequately verified and validated. In the 
event that current technology and/or data base are insufficient to judge the correctness of the assumptions, Technology Development Needs (TDNs) are specified. These TDNs identify experimental programs for obtaining improved or additional technology and/or data. The MHTGR conceptual design requirements are given in Ref. 6. The specific core physics technical requirements relevant to this V\&V program are given in Table 2-1. The uncertainties assumed in the calculation of the physics parameters for the conceptual design selections are sumarized in Table 2.2; and the steps required to validate that the methods used can indeed calculate these parameters with the required accuracy are given in Table 2.3 .

The flow diagram in Fig. 2-1 illustrates the method validation process. As noted in the figure, the method is validated if the existing data base is sufficient or another validated code can be used for comparison. The figure also deplets the "iterative" manner, which may be needed to complete method validation.

The actual validation procedure used in Steps 4 and 10 is illustrated in Fig. 2-2. It consists of plotting the available measurements for the parameter in question against the corresponding predictions made using the method to be validated. A $45 \mathrm{deg}$ line, plus bounding lines corresponding to the required accuracy $\left(e_{.} g_{\cdot}, \pm 20 \%\right)$ are also drawn. Perfect agreement would be indicated by all the points lying on the $45 \mathrm{deg}$ 1ine. A "best fit" straight line is then drawn through the data points along with the corresponding $95 \%$ confidence intervals. If this best fit line and the $95 \%$ confidence intervals lie within the bounding Interval for the $45 \mathrm{deg}$ line; then the method has been validated, i.e., shown to calculate the parameter to within the uncertainty given by the bounding lines with a $95 \%$ confidence level.

If the available data is such that a $95 \%$ confidence statement cannot be made with respect to the uncertainty level in the calculational method. Then other validated methods can be used for comparison or additional TDNs planned. 
TABLE 2-1

CORE PHYSICS TECHNICAL REQUIREMENTS

\section{Goa1 1}

- Meet ducy cycles; 1.e. provide sufficient poison worth to control excess reactivity, load following, xenon, $\mathrm{Pa}-233$, and other normal transients.

- Ensure negative temperature coefficient over normal operating range.

- Control power level and ensure stable power distribution.

- Maintain reactor in cold. safe shutdown condition indefinitely $\left(\mathrm{K}_{\text {eff }} \leq 0.99\right.$ at fuel temperature of $23^{\circ} \mathrm{C}\left(73^{\circ} \mathrm{F}\right)$.

- Maintain reactor shutdown $\left(\mathrm{K}_{e f f} \leq 0.99\right)$ during refueling at a core inlet temperature of $\leq 121^{\circ} \mathrm{C}\left(250^{\circ} \mathrm{F}\right)$.

- Maintain maximum time-average fuel temperature $\leqslant 1250^{\circ} \mathrm{C}\left(2282^{\circ} \mathrm{F}\right)$ during normal operation.

\section{Goal 2}

- Meet duty cycles.

\section{Goal 3}

- Malntaln reactor shutdown $\left(\mathrm{K}_{\text {eff }} \leq 0.99\right)$.

- Meet duty cycles.

- Ensure negative temperature coefficient for all potential accident temperatures.

- Limit peak fuel temperature to $\$ 1600^{\circ} \mathrm{C}\left(2912^{\circ} \mathrm{F}\right)$ as a rule of thumb during conceptual design. 
TABLE 2-2

CORE PHYSICS ASSUMPTIONS

\begin{abstract}
The core physics experimental data base is adequate to ensure that the temperature coefficient can be calculated with an uncertainty of $\leq \pm 20 \%$.

The core physics experimental data base is adequate to ensure that the power distributions can be calculated with an uncertainty of $\leq \pm 13 \%$.

The core physics experimental data base is adequate to ensure that the control rod bank reactivity worth can be calculated with an uncertainty of $\leq \pm 10 \%$.

The core physics experimental data base is adequate to ensure that the core reactivity can be calculated at nominal full power conditions with an uncertainty of $\leq \pm 1.5 \% \Delta \rho$.
\end{abstract}


TABLE 2-3

STEPS FOR METHODS VALIDATION

1. Identify computational methods utilized to assess if plant design requirements are met.

2. Identify key assumptions related to input data, models, and/or method; and determine sensitivity of results to these assumptions.

3. Based upon the accuracy specified for meeting plant design requirements, specify the required accuracy for the method.

4. Review the existing data base to determine if required accuracies are met.

5. In cases where the existing data base is insufficient or other validated methods are unavailable, identify TDNs to validate design methods over the appropriate range of test conditions.

6. Perform calculations needed to support TDN experiment definition.

7. Based upon the required accuracies for meeting design requirement plant goals, allocate desired accuracies for method, component model, and/or input data.

8. Perform method calculations that simulate TDN experiments.

9. Perform a sufficient number of experiments to obtain a valid statistical distribution.

10. Compare method calculation results with experimental results and judge acceptability relative to the required accuracy.

11. In cases where the method is not shown to satisfy the required accuracies, determine if method refinement increased design margins (to accomodate larger uncertainties) and/or additional technology development is needed. 


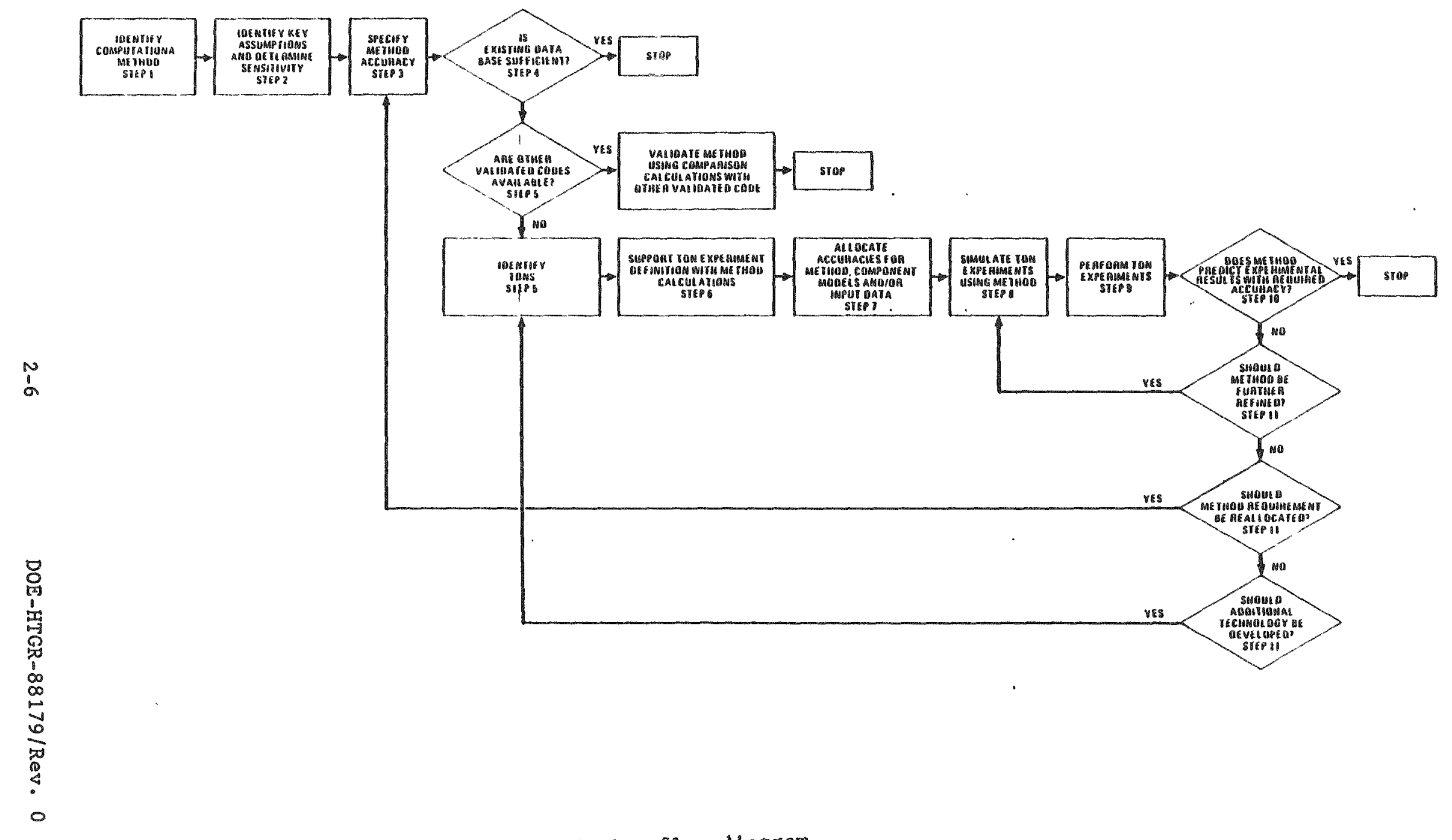


PC $-000280 / 0$

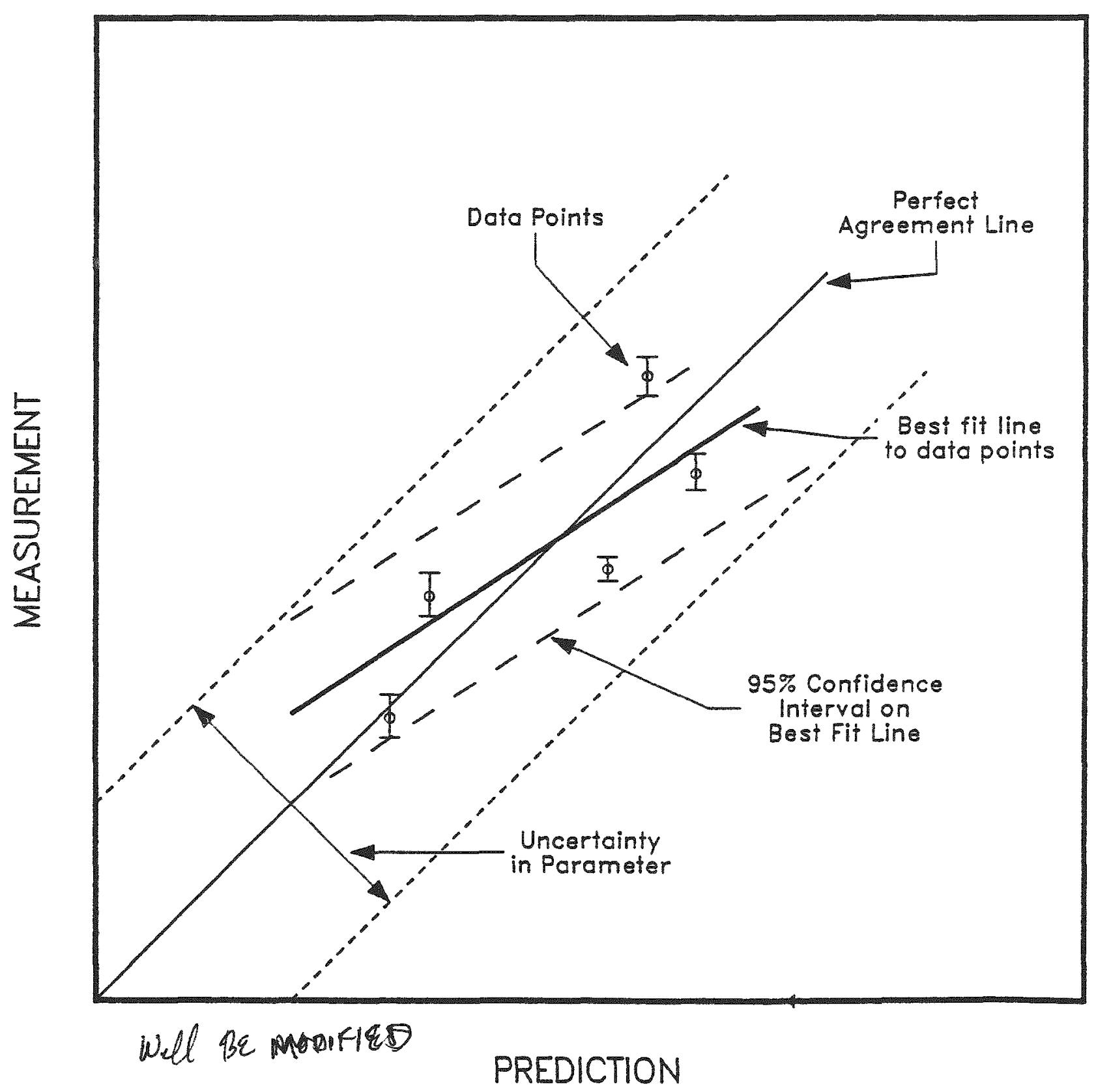

Fig. 2-2. Illustration of validation procedure for reactor physics methods 


\subsection{VERIFICATION AND VALIDATION CRITERIA}

It is required within the MHTGR program to demonstrate that the presumed accuracies listed in Table $2-2$ are met. These accuracies are demonstrated utilizing V\&V procedures. The V\&V of computational methods and codes used within the MHTGR program will be performed utilizing the set of criteria defined within this section. Sections 2.2 .1 and 2.2 .2 sumarize industry standards and regulatory guides deemed applicable to V\&V of MHTGR computational methods. These regulations and standards give general guidelines that were, in general, developed for light-water reactors; therefore, they will be interpreted and used only as they apply to the MHTGR. Based upon the guidelines within these regulations and standards, a set of V\&V definftions, requirements, and guidelines are defined in Section 2.2 .3 which express the intended V\&V practices within the MHTGR program.

\subsubsection{Industry Standards}

This section sumarizes industry standards which provide guidance for V\&V of scientific and engineering codes and have been applied to the V\&V of computational methods used within the MHTGR program.

Quality Assurance (QA) program guidelines for design analyses are found in ANSI/ASME NQA-1-1986 (Ref. 7). This standard requires that computer programs utilized for design analysis shall be verified, validated, and controlled to assure that changes are documented appropriately. It lists documentation guidelines for computer programs such as identification and verification of analysis assumptions and input parameters. The MHTGR computational method V\&V procedures will follow these guidelines.

A more comprehensive statement of industry guidelines for code V\&V is found within ANSI/ANS 10.4 (Ref. 8). This standard contains recommendations for V\&V activities which may be applied to scientific and 
engineering computer programs being developed (performed in parallel) and already being utilized (performed a posteriori) within the nuclear industry. The recomendations for a posteriori V\&V will be utilized within the MHTGR program. Other standards considered include Refs. 9 through 16.

\subsubsection{Regulatory Guidance}

The NRC also provides guidance on the integral role code V\&V plays in $Q A$ and the systematic manner in which code V\&V should be performed. This section summarizes NRC guidance on V\&V definitions and procedures which has been applied in the METGR program.

Appendix B, "QA Crlterla for Nuclear Power Plants and Fuel Reprocessing Plants," to 10CFR50 "Licensing of Production and Utilization Facilities" (Ref. 17), established the need for applicants to demonstrate that the methods utilized in reactor design are verified and validated. Additional guidance for NRC QA requirements is found in Regulatory Guides 1.64 and 1.28 (Refs. 18 and 19, respectively). The more recent of these guides endorses the QA program requirements for design analysis stated within the 1983 version of the ANSI/ASME NQA standard described in Section 2.2.1 (Ref. 20). However, the sections of ANSI/ASME NQA-1-1986 pertinent to design analysis (Sections 3 and 4) have not been changed from those in ANSI/ASME NQA-1-1983. None of the above guides were found to provide sufficient detail into actual V\&V procedures, although the MHTGR is designed to meet 10CFR50, Appendix B.

Although not incorporated into regulation, NUREG-0856-F (Ref. 21) provides additional insight into the level of detail expected in V\&V. This NUREG contains definitions for V\&V and documentation guidelines for computational methods utilized in high-level waste management. It is indicative of the NRC attitude that a systematic procedure for computational method V\&V is an essential part of QA. Definitions within 
NUREG-0856-1 have been adopted within this plan as discussed below. other regulations considered in formulating this plan are given in Refs. 22 through 25.

2.2.3. Definitions, Requirements, and Guidelines Selected for Verification and Validation

From the above mentioned industry and regulatory sources, a set of definitions, requirements, and guidelines have been selected for verifying and validating that the analytical methods and codes meet MHTGR program technical requirements. These criteria, which are listed in Table 2-4, express the intent of V\&V practices within the MHTGR program.

Definitions were obtained from NUREG-0856-F (Ref. 21). Parenthetical coments have been added to these definitions to clarify their meaning as shown in Table 2-4. These definitions also satisfy the intent of the V\&V definitions stated within ANSI/ANS 10.4 (Ref. 8).

Requirements specified in Table $2-4$ have been selected as the minimum requirements necessary for computational methods to satisfy the definitions of V\&V. Verification shall be accomplished via benchmark comparisons with known solutions, hand calculations, or other verified codes. Validation shall be accomplished by comparing verified model results with one of the following: experimental data, an analytic solution to a validated model, or other (validated) code results.

Table 2-4 also lists guidelines for a posteriori method and code V\&V, which are based upon recomendarions found within ANSI/ANS-10.4 for V\&V of existing programs (Ref. 8). As noted in Ref. 8, a posteriori V\&V plans should identify the type, objective, and requirements specific to the method or code on which the V\&V is performed. In cases where a comprehensive verification program is desired, the checklists specified in ANSI/ANS-10.4 for verification of developing codes (parallel verification) may be utilized. These checklists will be used to assess the code programing structure and format, completeness, correctness and consistency, and documentation. In Ref. 8, it is also suggested that 


\section{TABLE 2-4}

DEFINITIONS, REQUIREMENTS, AND GUIDELINES FOR VERIFICATION AND

VALIDATION OF COMPUTATIONAL METHODS UTILIZED IN MHTGR ASSESSMENTS

DEFINITIONS (a):

Verification: Assurance that a computer code correctly performs the operations specified in a numerical model (i.e., demonstrates substantially identical results when compared to known solutions).

Validation: Assurance that a computational model is a correct representation of the process or system for which it is intended ( $1 . e$. , demonstrates that a verified model adequately correlates with experimental data, reactor operating data, etc.).

REQUIREMENTS (b) :

Verlfication: Results shall be verified by benchmark comparison with known solutions, hand calculations, or other verified results.

Validation: Verified code results shall be validated using one of the following three methods: comparison of results with experimental data, an analytic solution to a validated model, or other (validated) code results.

GUIDELINES FOR A POSTERIORI V\&V:(c)

- Information should be provided on:

- The class of problems for which the program is utilized.

- The physical model on which the program is based.

- Solution algorithms or numerical approximations used to represent the mathematical model.

- Range of program responses that may be considered valid or criteria to be used in evaluating the validity of program responses.

- Auxiliary programs or input bases to be utilized by the program.

- The user environment in which the program will be utilized (hardware, software, or user interface requirements). 
TABLE 2-4 (Continued)

- The V\&V plan should Identify:

- Reason(s) why a posteriori V\&V is to be performed.

- Scope and objectives for the level of ViV selected.

- The analytical tools to be used in the V\&V.

- Depending upon the extent of past V\&V activities, the V\&V may range from a simple demonstration that the program produces reasonable results for representative sample problems to a comprehensive verification of program requirements, design, coding, test coverage, and evaluation of test results. In cases where a comprehensive V\&V is desired, the following procedures may be applied:

Verification: The program design should be verified, utilizing the Ref. 8 checklists for programing structure, completeness, consistency and correctness, and documentation.

Validation: The validation tests should be reviewed to determine that a sufficient number are performed which consider all important program features and anticipated program applications.

\footnotetext{
(a) Based upon definitions given in NUREG-0856-F (Ref. 21).

(b) Quantitative V\&V criterion for each method provided in Section 4.

(c) Based upon information in ANSI/ANS 10.4, Section 11 (Ref. 8).
} 
more extensive validation procedures of existing methods carefully evaluate the adequacy of validation tests; $1 . e$. , to ensure that the number of tests were sufficient, demonstrate that all requirements are satisfied, and the combination of test results meet the acceptance criteria specified by the user. Furthermore, the quality of the sests should be reviewed to ensure that they indicate repeatable, reliable, or expected behavior.

2.3. CONTROL OF VERIFIED AND VALIDATED COMPUTATIONAL METHODS

Once a version of the analytical methods and codes have been verified and validated using the guidelines in Table 2-4, this version of the method shall be utilized for MHTGR analyses. Prior to incorporating any changes into this version, it must be established that the revision meets $V \& V$ guidelines in Table $2-4$ and that the modification does not preclude the method from meeting program requirements in Section 2.1. 


\section{DESCRIPTION OF DESIGN METHODS}

Core physics design parameters are typically generated using the static, depletion, and kinetic codes specified in Fig. 1-1. However, prior to the use of these codes, significant data processing is required to generate input for the design codes. Brief descriptions of the computer codes and how they are used to generate the core physics design parameters is given in the following sections. The detailed procedure, methods, etc., will be given in the core physics methods validation reports.

\subsection{DESIGN CODE INPUT DATA PROCESSING}

Current GA neutron cross sections used for MHTGR design are a combination of ENDF/B-I, ENDF/B-II, and ENDF/B-III cross section sets. The ENDF first became available in 1967 from a national program through a cooperative effort of government, university, and industry. This program, carried out by the Cross Section Evaluation Working Group (CSEWG), provides for periodic evaluations of the data for all important nuclides. Results of such evaluations are stored in the ENDF/A and ENDF/B libraries. The ENDF/A library is a general purpose collection which may include several evaluations for one material or partial evaluations covering a single cross section or a limited energy range. The ENDF/B library is a reference set which contains only a single complete evaluation for each material at a given time. The evaluations to be incorporated in the ENDF/B library are designated by the CSEWG after a perlod of testing which includes calculations of appropriate critical experiments. The complete set of evaluations in the ENDF/B library is updated to incorporate new measurements every several years and designated by a version number. The most recent evaluation is Version V. Currently Version VI is being generated and evaluated by the 
CSEWG. When it is released for use, it will become the reference data set for MHTGR nuclear calculations

The CSEWG effort began with data sets obtained primarily from thermal reactor design groups. ENDF/B Versiors II, III, and IV were funded primarly by the 1iquid metal-cooled, fast breeder reactor (LMFBR) effort, and the ENDF/B-V library development was strongly influenced by the desire of the Electric Porar Research Institute (EPRI) to obtain data that could be used without adjustment for commercial light-water reactor (LWR) design calculations. The selection of data that yields good initial criticality results for an LWR system will not necessarily be appropriate for a LEU HTGR system.

Further, it is important to remerber that the most recent cross section evaluation 2 not always the best evaluation for all systems. Therefore, GA continues to maintain their current reference cross section library, which is a combination of ENDF/B-I, ENDF/B-II, ENDF/B-III.

Significant data processigg is required to convert these ENDF/B librarles into cross section flies for use in GA design codes. Neutron cross section files are generated from the ENDF/B card image tapes and from expsting GAM and GATHER tapes using various data processing. These cross section data files are then used in the MICROX code to generate temperature- and loading-dependent broad group cross sections over a specified energy range.

These broad group cross sections, in conjunction with the output from other auxiliary and data preparation codes comprise the basic input for the design calculations. 


\subsection{DESIGN CODE DESCRIPTION}

The basic nuclear design calculations are performed using the static, depletion, and kinetic codes specified in Fig. 1-1 and described briefly below:

- DTFX is the GA version of the LASI code DTF-IV. This code is a one-dimensional, multigroup program for solving the neutron transport equation using the $\mathrm{Sn}$ method. The program can determine the regular or adjoint solution for slab, cylindrical, or spherical geometry. Isotropic or a form of linear anisotropic scattering may be considered. DTFX is used primarily for generating shielding factors or boundary conditions for poison materials for use in the static and depletion diffusion codes.

- FEVER is a one-dimensional muleigroup neutron diffusiondepletion program which calculates the spatial distribution of the neutron flux for each neutron energy group, the effective multiplication factor, and spatial composition of a reactor For a specified period of time and for the reactor operating conditions specified by the user. FEVER is used for the calculation of radial or axial zoning factors and power distributions, for depletion analyses, and for material reactivity worth.

- TEMCO is a one-dimensional multigroup neutron diffusion program which calculates the spatial distribution of the neutron flux for each neutron energy group, the effective multiplication factor, and the temperature coefficient for the reactor operating temperatures for which the user supplies cross sections. TEMCO is just an extension of the FEVER code, which calculates the neutron flux and power distributions, and the multiplication factor using the one-dimensional diffusion 
theory. Additionally, TEMCO calculates the contribution of each individual nuclide to the overall temperature coefficient.

- GAUGE is a two-dimensional, multigroup neutron diffusion theory code in which equations for a uniform triangular mesh are solved to obtain the multiplication factor and the spatial flux and power distribution of reactors with hexagonal core configuration. Complete reactor life histories with partial refueling at a number of reload time points can be calculated. At each discrete time point, a control rod search may be performed to maintain criticality at all times. The depletion scheme of all burnable nuclides is specified by the user at execution time. Three modes of operation are possible: (1) straight burnup calculation; (2) control rod criticality search, allowing the adjustment of a number of control rod banks according to a prescribed rod sequencing scheme; and (3) a series of static calculations with allowance for insertion of rods into fixed prescribed positions.

GAUGE is used extensively for calculation of the temperaturedependent multiplication factor (and, hence, control rod and other material reactivity worth), fine mesh power distributions, and depletion analyses.

- $2 D B$ is a two-dimensional, multigroup neutron diffusion theory code in $X-Y, R-Z, r-\theta$, or triangular geometry. This program calculates spatial neutron flux and power distribution and the effective multiplication factor. The original 2DB was developed at Battelle Northwest Laboratories (BNWL) and has been changed only as required for HTGR analyses. 2DB is used for calculation of the radial and axial power distribution, multiplication factor, control rod, and other material reactivity worth. 
- DIF3D is a one-, two-, or three-dimensional few group nodal neutron diffusion-transport theory code in $X-Y, R-Z$, or triangular geometry. DIF3D calculates the spatial neutron flux and power distribution and the effective multiplication factor. This code was originally developed at the Argonne National Laboratory (ANL). The GA version of this code differs from the original version only in the changes required for computer conversion. DIF3D is used for calculation of the power distrlbutions, multiplication factor, control rod reactivity worth, and for depletion analyses.

- GARGOYLE is a zero-dimensional, multigroup program which determines the fuel feed requirements for full and/or partial zefueling during each fuel cycle. This code is used to provide fuel cycle and fuel loading input to the design codes.

- BLOOST is a space-independent neutron kinetics code combined with a two-dimensional transient heat transfer code. This code is used to predict the time-dependent behavior of the aewron flum associated changes in core power density and temperature during operating transients and reactivity accidents.

\subsection{DESIGN PARAMETERS}

The calculational method for the basic core physics parameters is described in the following sections. These methods use the computer codes described above.

\subsubsection{Temperature Coefficient}

The temperature coefficient calculational method is shown in Fig. 3-1. The temperature coefficient may be calculated using the onedimensional codes FEVER or TEMCO, and/or the two-dimensional codes GAUGE 


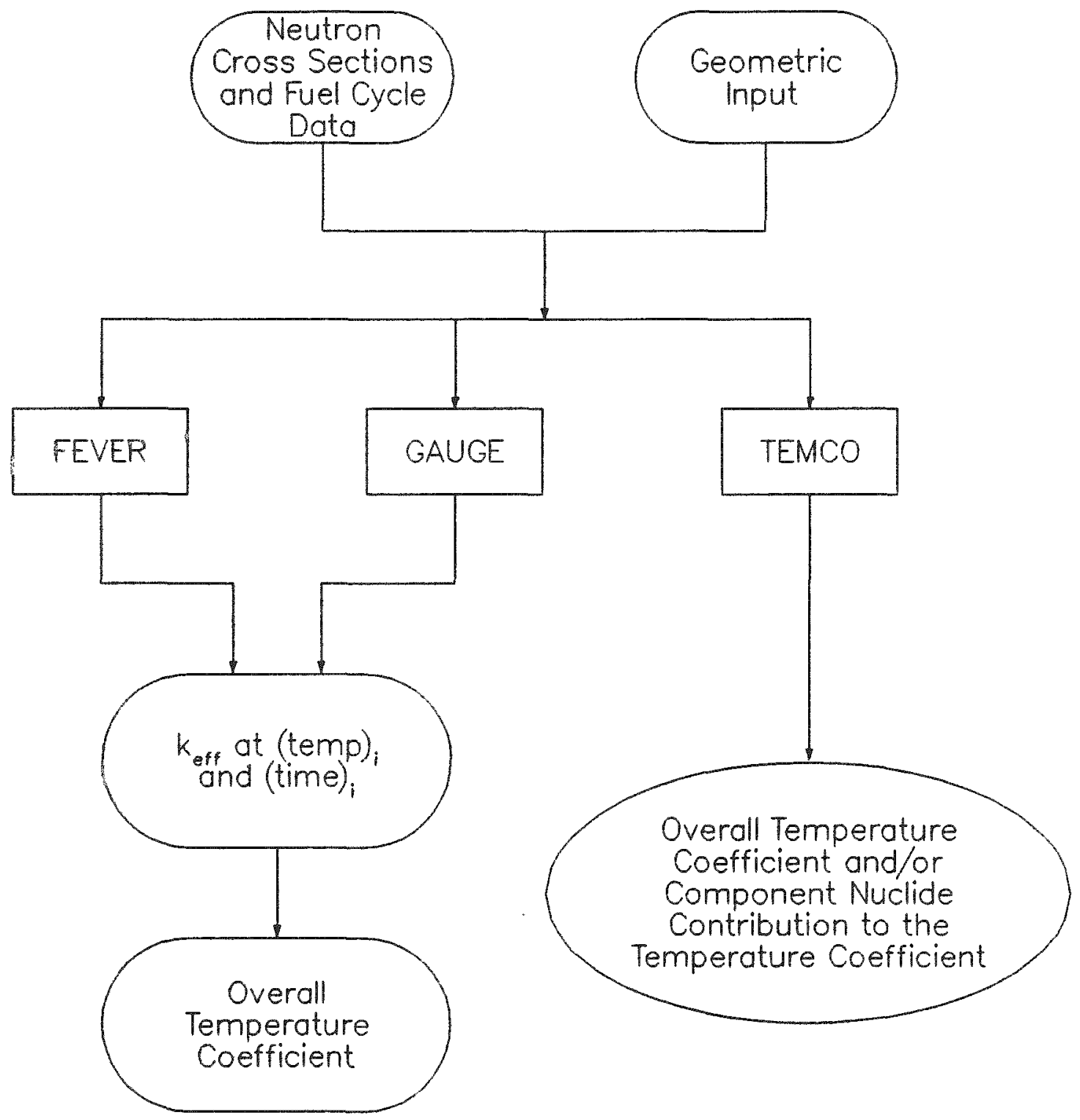

Fig. 3-1. Temperature coefficient calculational methods 
or 2DB. The use of FEVER, GAUGE, and 2DB involves a series of static calculations at different temperatures for different times in the operating cycle. The overall temperature coefficient is then the slope of the reactivity versus temperature curve. The TEMCO calculation differs from FEVER only in that it permits calculation of the component nuclide contributions to the temperature coefficient.

\subsubsection{Control Rod (and Other Material) Reactivity Worth}

The control rod (and other material) reactivity worth calculational method is shown in FIg. 3-2. The-control poison (and other material) reactivity worfh may be calculated using the two-dimensional codes GAUGE and $2 D B$ and the three-dimensional code DIF3D. Each of these codes calculates the multiplication factor at a specific time and temperature from which the reactivity worth, $\Delta p$, is determined.

\subsubsection{Core Neutron Flux and Power Distribution}

The method for calculating the neutron flux/pon is shown in Fig. 3-3. The axial distributions may be calculated using the one-dimensional code FEVER, the two-dimensional code 2DB, and/or the three-dimensional code DIF3D. The radial distributions may be calculated using the two-dimensional codes GAUGE and $2 D B$ and/or the threedimensional code DIF3D. These neutron flux/power distributions may be calculated as a function of time and temperature for specified fuel loadings and/or zoning.

\subsubsection{Decay Heat Production}

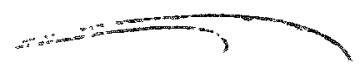

The decay heat production(may be calculated using the zerodimensional diffusion-depletion code GARGOYLE." The GARGOYLE code used in decay heat analyses is a special version which uses a library of approximately 1100 nuclides. The decay heat production may then be calculated, at any time in life, as a function of time after reactor shutdown. 
PC-000280:

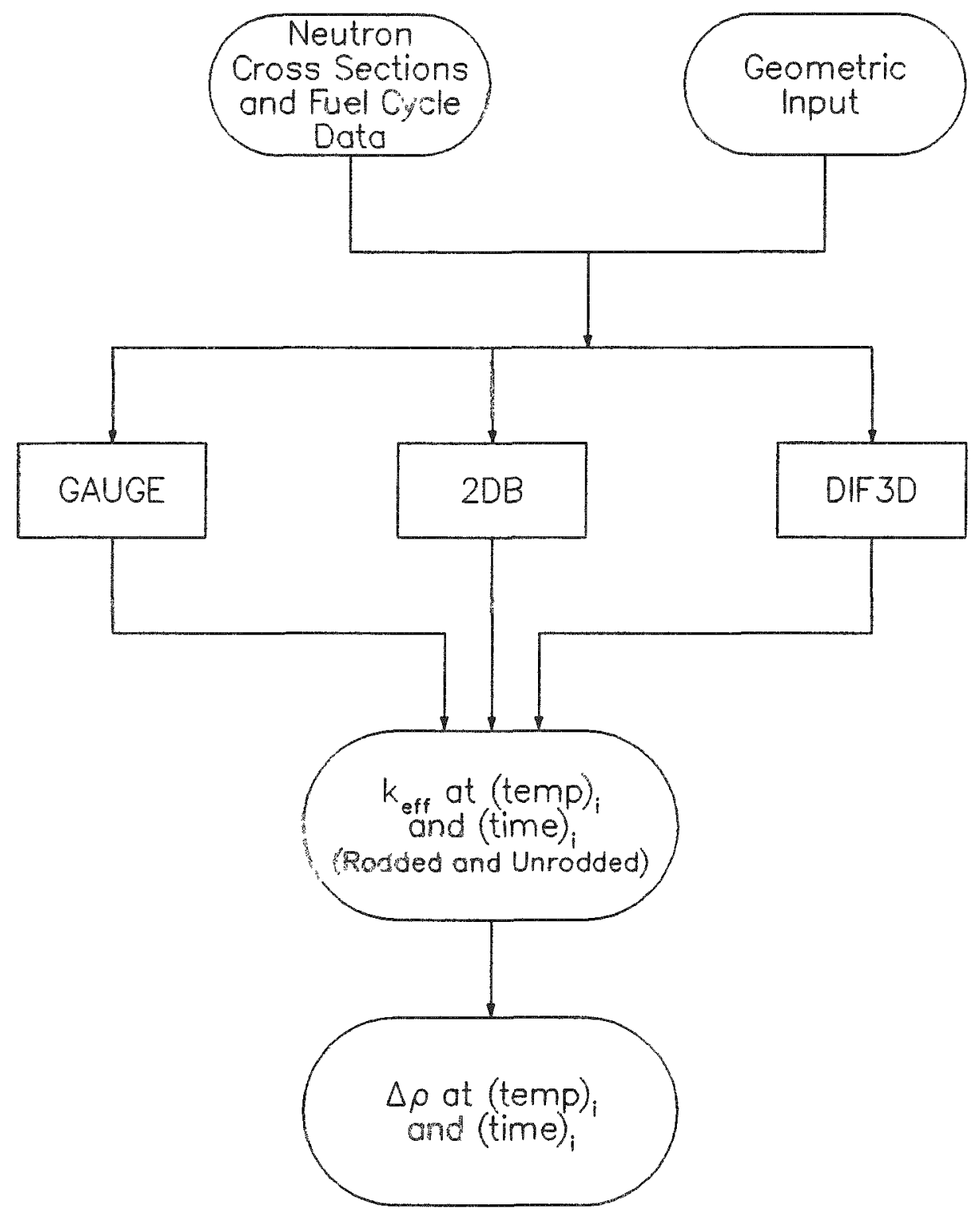

Fig. 3-2. Control rod reactivity worth calculational methods 


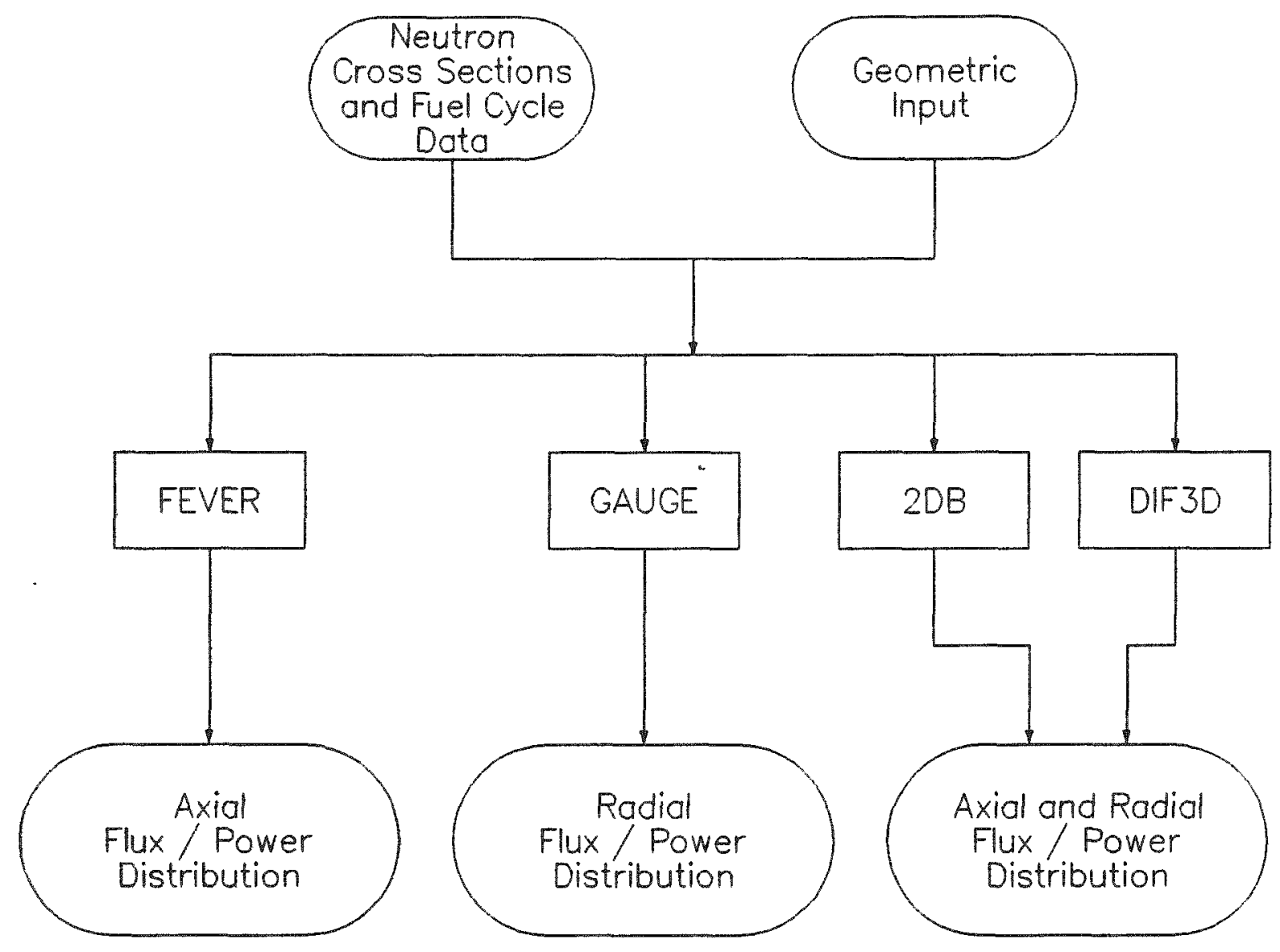

Fig. 3-3. Core neutron flux/power distribution calculational methods 


\section{VERIFICATION AND VAIDDATION OF DESIGN METHODS}

GA core physics methods have, in general, been validated for HEUL Th-fueled HTGR. Most of the experimental data were derived from HTGRtype critical experimenes performed at GA and from the operation of the $P B$ and FSV reactors. The MHTGR with LEU/Th fuel requires a reassessment of these methods. This assessment will include one or more of the following, as described in section 1.3:

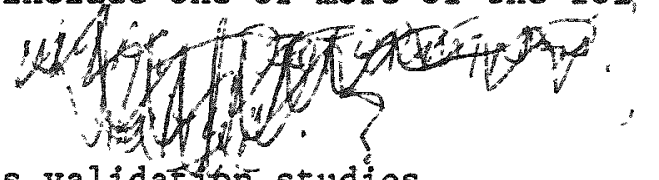

- Reanalysis of selected previous validation studies.

- Documentation of selected previous validation studies.

- Comparison of new experimental data to GA calculations.

- Comparison of other (non-GA) calculations with GA calculations.

A major emphasis of this program will involve reanalysis and/or documentation of selected previous validation studies. Many of these studfes were done years ago with other than the current cross sections and/or methods. Selected recalculations using the current reference cross sections and methods will be sufficient to justify the use of these previous studies in the validation program. In addition, it is planned to obtain new supplemental IEU fuel experimental data as was discussed in Section 3.3 .3 .

The principal sources of experimental data (FSV, $P B$, etc.) which can be used to validate the MHTGR physics methods are given in Table 4-1, along with a listing of the key physics parameters (temperature coefficient, control rod worth, etc.) which are measured. Thus, Table 4-1 summarizes the data base available to validate the physics methods used to calculate these parameters. 
TABLE 4-1

EXPERTMENTAI. DATA AND APPLICABILITY TO VALIDATION PROGRAM

\begin{tabular}{|c|c|c|c|c|c|c|c|c|c|c|c|}
\hline & \multicolumn{11}{|c|}{ Exper lmental Data } \\
\hline & $\begin{array}{c}\text { PI } \\
\text { Criteal }\end{array}$ & $\begin{array}{c}\mathrm{PB} \\
\text { Operation }\end{array}$ & $\begin{array}{c}\text { HTGR } \\
\text { Critical }\end{array}$ & $\begin{array}{c}\text { FSV } \\
\text { Operation }\end{array}$ & $\begin{array}{c}\text { HTLTR } \\
\text { Experiments }\end{array}$ & $\begin{array}{c}\text { AVR } \\
\text { Opexation }\end{array}$ & $\begin{array}{l}\text { Virre } \\
\text { Critical }\end{array}$ & $\begin{array}{c}\text { CNPS } \\
\text { Critical }\end{array}$ & $\begin{array}{l}\text { Dragon } \\
\text { Reactor }\end{array}$ & $\begin{array}{l}\text { HITREX-2 } \\
\text { Critical }\end{array}$ & $\begin{array}{c}\text { KAHTER } \\
\text { Critical }\end{array}$ \\
\hline \multicolumn{12}{|c|}{ Phys ics Parameter } \\
\hline $\begin{array}{l}\text { Temperature } \\
\text { coeffictent }\end{array}$ & $*(a)$ & $*$ & * & * & * & * & * & $*$ & $*$ & $-(b)$ & $-\infty$ \\
\hline $\begin{array}{l}\text { Control rod } \\
\text { reactivity } \\
\text { worth }\end{array}$ & $*$ & $*$ & * & * & -- & $*$ & $*$ & * & * & -- & $*$ \\
\hline $\begin{array}{l}\text { Core neutron } \\
\text { flux (power) } \\
\text { distributions }\end{array}$ & $*$ & $*$ & -- & * & -- & -- & * & * & $*$ & * & $\star$ \\
\hline $\begin{array}{l}\text { Core critl- } \\
\text { calty and } \\
\text { material } \\
\text { worth }\end{array}$ & $\nRightarrow$ & $*$ & $\star$ & * & -- & $\star$ & * & * & -- & $*$ & $\star$ \\
\hline $\begin{array}{l}\text { Water Ingress } \\
\text { reactivity } \\
\text { worth }\end{array}$ & $*$ & -- & -- & -- & - & -- & -- & * & - & -- & (c) \\
\hline Decay heat & -- & -- & $-\infty$ & -- & $-\infty$ & $*$ & -- & -- & -- & -- & -- \\
\hline
\end{tabular}

(a)* = data avallable or expected to be available for valldation program.

(b) -- = no data avallable from this component to valldate the corresponding parameter.

(c) KFA subcrtica1. 
A detailed description of the specific methods validation program is given in the Sections 4.1 through 4.6 for each parameter 1isted in Table 4-1. The verification program for each of the codes used in these methods (see Section 3 ) is described in Section 4.7.

\subsection{TEMPERATURE COEFFICIENT}

The methods used to calculate the MHTGR core temperature coefficient are described in Section 3 . The main computer codes used are MICROX, FEVER, and TEMCO. The verification of these codes is described in Section 4.7.

\subsubsection{Validation Status}

The methods for temperature coefficient calculations for HTGRs using HEU fuel were validated for the licensing of the FSV reactor using measurements from PB reactor operation plus doppler coefficient experiments conducted on the HTGR critical assembly. Since that time, further data has been obtained from measurements during operation of the FSV reactor and experiments conducted on the High-Temperature Lattice Test Facility.

For the conceptual design of the MHTGR using LEU fuel, an estimate was made of the uncertainty associated with the method for calculating temperature coefficients of $\neq 10 \%$. This estimate was based on data from several sources including the HEU validation work discussed above. Specifical1y:

- The measured temperature defect from which the temperature coefficient is calculated (reactivity change over a specified temperature range) for the PB HTGR, which was a sma11, graphite, high leakage core like the MHTGR, and agreed with the calculated value to within $4 \%$. 
- The FSV HTGR temperature defect measurements, which include xenon effects, and agreed with calculations to within $10 \%$ (Ref. 30).

- Doppler coefficient measurements on Th-23? made in the HTGR critical assembly which agreed with the calculations to within $6 \%$ (Ref. 39).

- Temperature coefficient measurements made in the HighTemperature Lattice Test Reactor (HTLTR) with a graphite assembly containing plutonium fuel which agreed with $G A$ calculations to within $6 \%$ (Refs. 26 through 29).

- Ko from depletion calculations on MHTGR type LEU fuel employing the MICROBURN code which agreed with similar calculations using the independently validated British WIMSD code to within $2 \% \Delta K$ in reactivity over a burnup of over $150,000 \mathrm{MWa} / \mathrm{MT}$. This is considerably more than the core average design burnup in the MHTGR $(98,400 \mathrm{MWd} / \mathrm{MT})$.

In summary, the data base used to assign uncertainty included operating HTGR reactors and critical experiments with HEU fuel, plus measurements and comparison calculations on LEU and plutonium fueled systems. Overall, the deviation between experiment and calculation was less than $10 \%$. Thus, a $10 \%$ uncertainty band was selected for the PSID temperature coefficient calculations.

\subsubsection{Validation Plan}

The following is a listing and discussion of the specific experiments to be used for validating the MHTGR temperature coefficient calculational methods to demonstrate that this parameter can be calculated with the required accuracy. The node numbers given along with the individual experiments and calculations refer to the schedule for 
the validation plan given in Section 5, Figs. 5-1 and 5-2, and can be used to locate the specific work items within the schedule:

4.1.2.1. PB Critical Experiments (Nodes 220 to 230). The overall temperature coefficient of the assembly was measured by electrically heating the core and reflector unfformly up to $\sim 260^{\circ} \mathrm{C}\left(\sim 500^{\circ} \mathrm{F}\right)$. Specifically two measurements of interest were made:

1. Measurement of the reactivity change during uniform heat up of the entre core and reflector assembly in small steps from room temperature to $474^{\circ} \mathrm{F}$.

2. Measurement of the reactivity change during uniform heat up of the entire core and reflector from room temperature to $204^{\circ} \mathrm{F}$.

These experiments will be reviewed and documented. The corresponding reactivity change and temperature coefficients will be calculated using MHTGR methods for comparison with the experiments. This assembly utilized fully enriched uranium plus thorium in graphite, but the comparison w111 provide a test of the ability of the methods to calculate doppler broadening of cross sections over a wide temperature range, plus the reactivity effects of temperature changes in the thermal spectrum in a graphite moderator.

4.1.2.2. HTGR Critical Assembly (Ref. 39) (Nodes 220 to 230). Five doppler coefficient measurements were made on the HTGR critical assembly with a lattice corresponding to a typical HTGR HEU fuel composition $(C / U=2500, C / T h=200)$. The central assembly was heated from room temperature ( 300 to $600 \mathrm{~K}$ ); and 211 measurements were made with that assembly having a $C / U=2500$. The $C / T h$ rarios measured were 100,200 , and 300 . In addition measurements were made with no thorium and with boron replacing the thorium.

The documentation on the temperature coefficient measurements made on this assembly will be reviwed and updated as necessary. Calculate 
the corresponding reactivity change and temperature coefficients using MHTGR methods and cross sections for comparison with the experiments. This assembly utilized fully enriched uranium plus thorium in graphite, but the comparison will provide a test of the ability of the methods to calculate doppler broadening of cross sections over a wide temperature range, plus the reactivity effects of temperature changes in the thermal spectrum in a graphite moderator.

4.1.2.3. HTLTR Assemb1y (Nodes 220 to 230). The HTLTR experiments were performed at BNWL (Refs. 26 and 27) with analytical support provided by GA (Ref. 28). The HTLTR facility was equipped with resistance heating elements that allowed zero-power critical reactor lattice experiments to be performed at temperatures ranging from room temperature to $1000^{\circ} \mathrm{C}$ $\left(1832^{\circ} \mathrm{F}\right)$. The primary objective of this series of experiments was to determine the temperature dependence of the infinite medium neutron multiplication factor, $k_{\infty}$, for lattice compositions and configurations of interest for HTGR lattices. Coefficients were measured in five different lattices, two of which are of greatest interest for MHTGR methods validation. These are the plutonium fueled lattice, and the U-235 fueled lattice.

These measurements have been carefully documented, and calculations will be performed using MHTGR methods for comparison with the experimental results.

4.1.2.4. PB Operation (Nodes 220 to 230). Isothermal temperature coefficient measurements were made at $100^{\circ}, 600^{\circ}$, and $1800^{\circ} \mathrm{F}$ at beginning of life in both Core 1 and Core 2. In addition, total temperature defect measurements were made in Core 1 during the first 300 EFPD of operation to determine the burnup dependence of the coefficient.

The temperature coefficient measurements will be reviewed and documented; and corresponding calculations made using MHTR methods for comparison with the experiments. This reactor utilized fully enriched 
uranium plus thorlum in graphite, but the comparison will provide a test of the ability of the methods to calculate doppler broadening of cross sections over a wide temperature range, plus the reactivity effects of temperature changes in the thermal spectrux in a graphite moderator, and fission product buildup effects.

\subsubsection{FSV Operacion (Ref. 30) (Nodes 220 to 230). Temperature} defect measurements have been made during the initial startup of the FSV core, and at the startup following each reload. These temperature defect measurements will be reviewed and documented; and corresponding caiculations made using MHTGR methods for comparison with the experiments. As in the case of PB, the FSV reactor utilized fully ensiched uranium plus thorium in graphite, but the comparison will provide a test of the ability of the methods to calculate doppler broadening of cross sections over a wide temperature range, plus the reactivity effects of temperature changes in the thermal spectrum in a graphite moderator, and fission product buildup effects.

\subsubsection{AVR Operation (Nodes 200 to 210). Temperature coefficient} measurements have been made on the AVR reactor at cold-just-critical and hot-operating conditions. These measurements have been performed over the life of the core frow the inltial all HEU fueling to the current state in with about $25 \%$ of the fuel is low enriched. The cold [ $\leqslant 130^{\circ} \mathrm{C}$ $\left.\left(266^{\circ} \mathrm{F}\right)\right]$ coefficient was determined during shutdown periods by measuring the subcriticality at different core temperatures. The hot $\left[\leq 950^{\circ} \mathrm{C}\right.$ $\left(1742^{\circ} \mathrm{F}\right)$ ] coefficlent was determined during operation by the change in coolant outlet temperature at constant power, using a calibrated rod curve (Ref. 29). Data will be obtained for three or four measurements selected to cover the range of fuel loadings in the core, and the corresponding temperature coefficients will be calculated with MHTGR methods. One case has already been selected, corresponding to a $25 \%$ IEU fuel content, and the measurement data has been obtained.

4.1.2.7. CNPS Measurements (Nodes 240 to 250). The temperature coefficient measurement made over a $50^{\circ} \mathrm{C}$ range near room temperature in this 
critical assembly will be calculated using MHTGR methods. This was a full (core and reflector) isothermal measurement, and the fuel used was $20 \%$ enriched LEU in particle form closely resembling that planned for the MATGR.

4.1.2.8. VHTR (Nodes 240 to 250). Proposals have been made to JAERI to obtain all of the available temperature coefficient of reactivity measuments that have been performed both for the whole core and for the central heated samples. In cooperation with JAERI, GA would also deterwine what (if any) additional, useful, coefficient measurements could be made, for example, on a central heated sample using $20 \%$ enriched MHTGRtype fuel, or fuel containing plutonium. This is one of the few experiments available for validation of IEU temperature coefficients.

4.1.2.9. Dragon (Nodes 240 to 250). Temperature coefficient measurements were made on the Dragon reactor during its operation. These data will be evaluated using MHTGR methods.

\subsection{CONTROL ROD REACTIVITY WORTH}

The verification of the MICROX, GAUGE, 2DB, and DIF3D codes used in the calculational method for the MHTGR control rod reactivity worth is discussed in Section 4.7 .

\subsubsection{Validation Status}

The control rod reactivity worth calculational method has been validated for HEU fueled systems, including PB, HTGR critical, FSV, and Dragon. This validation was done by comparison of the measured and calculated control rod reactivity worth, as discussed below.

4.2.1.1. Peach Bottom. The reactivity worth of the PB control rods was measured during the initial startup and rise-to-power. These control rod reactivity worths and total shutdown bank worths were predicted to 
within $\neq 5 \%$ with the same or similar models and rod poison cross section development as currently in use at GA.

4.2.1.2. HTGR Critical. Measurements of the reactivity worth of both single rods and control rod pairs were made in the HTGR critical assembly (Ref. 39). Comparisons of these measurements to calculations indicated that single rod worths were overestimated by $\sim 4 \%$ and the control rod pair worths were overestimated by $\sim 11 \%$.

4.2.1.3. Fort St. Vrain. Control rod pair reactivity worths have been measured during the initial rise-to-power for each cycle (Ref. 30 ). Comparisons of the measured and calculated integral reactivity worth of control rod groups over these three cycles of operation show that the difference is typically $\leq 5 \%$ for the cumulative worth with the low worth rod groups having a higher measurement uncertainty.

4.2.1.4. Dragon. Numerous measurements of the control rod reactivity worth have been made in the Dragon reactor (Refs. 33 and 34 ). In the Dragon reactor, which has its control rod bank in the graphite reflector and is closest to the MHTGR design in this regard, the calculated control bank worth using GA developed models agreed with the measured value to within $11 \%$. Significanty, the calculation underestimated the actual bank worth.

\subsubsection{Validation Plan}

The following is a listing and discussion of specific experiments which will be used for validating the methods for evaluating the MHTGR control rod reactivity worth to demonstrate that it can be calculated with the required accuracy. A very large number of control rod worth measurements are available from the sources discussed above. A representative selection of these measurements, for which documentation is available that meets validation standards, will be used in this program. The schedule for this work is given in section 5, Figs. 5-1 and 5-3. 
4.2.2.1. PB, HTGR Critica1, FSV, and Dragon (Nodes 630 to 635). Control rod worth calculations for HTGR single rod measurements, for selected $P B$ and FSV measurements, and for the documented Dragon reactor data will be repeated using the current neutron cross sections and methods. Comparison of these calculations with the measured data, as described above, will justify the use of the previous comparison in this program. These comparisons will then be documented. In addition, previous comparisons will be documented, as required.

4.2.2.2. AVR (Nodes 600 to 620 and 660 to 670). A large number of measurements of control rod reactivity worth have been made during AVR operation from cold shutdown to full operating conditions. While the primary fuel is HEU, measurements have also been made as LEU fuel has been added to the core. The control rods in the AVR are located in graphite "noses" which jut into the core. Calculations will be done for selected AVR measurements over its lifetime as the fuel composition changes, and comparison of these calculations with the measured data will be made and documented. In addition, these calculations will be compared to the calculations done by AVR personnel.

4.2.2.3. CNPS (Nodes 640 to 670 ). The reactivity worth of $\mathrm{B}_{4} \mathrm{C}$ has been measured in the LEU-fueled CNPS critical assembly. In addition, the possibility of measuring the worth of a single $\mathrm{B}_{4} \mathrm{C}$ control rod located in the side reflector is being investigated. Calculations of the $B_{4} C$ reactivity worth and of the reflector control rod worth will be made and compared to the measured data. These calculated worths will then be compared to those done at CNPS and all comparisons will be documented.

4.2.2.4. VHTRC (Nodes 640 to 670). As a part of the cooperative program with JAERI, experiments have been proposed for the measurement of the reactivity worth of boron control rods located in reflector blocks immediately adjacent to the active core in the VHTR critical assembly. These control rod reactivity worths will be calculated and compared to 
both the measured data and to the JAERI calculations. All comparisons wi11 be documented.

\subsection{CORE NEUTRON FLUX AND POWER DISTRIBUTIONS}

The verification of the MICROX, FEVER, GAUGE, 2DB, and DIF3D codes used in the calculational method for the core neutron flux and power distributions is discussed in Section 4.7.

\subsubsection{Validation Status}

The core neutron flux and power distribution calculational method has been validated using comparisons of measured and calculated data from PB, FSV, and the HITREX II criticals, as discussed below.

4.3.1.1. Peach Bottom. Axial and radial neutron Elux distribution measurements were made in the initial core of the PB reactor. Measurements were made for both rodded and unrodded conditions. Comparison of these data with calculations have shown that $~ 85 \%$ of the data points agree to within $\pm 10 \%$.

4.3.1.2. Fort St. Vrain. Axial flux measurements were made in the FSV core during initial startup tests for rodded, unrodded, and partially rodded regions, and for regions adjacent to partially rodded regions (Ref. 35). The agreement between measured and calculated distributions was within $\pm 10 \%$ for all regions. Radial power distributions were measured over three cycles. Calculations generally agreed with these measurements to $\sim 10 \%$ except in few reglons where large measurement errors existed.

4.3.1.3. HITREX II. Fast and thermal flux distribution measurements have been made in this high-temperature reactor experiment (HITREX) critical assembly (Refs. 36,37 , and 38 ). The calculated distributions agreed with the measured within about $10 \%$. 


\subsubsection{Validation Plan}

The following is a listing and discussion of specific experiments which will be used for validating the methods for evaluating the MHTGR core neutron flux and power distributions to demonstrate that these methods calculate the parameters with the required accuracy. The schedule for this work is given in Section 5, Figs. 5-1 and 5-4.

4.3.2.1. PB, FSV, and HITREX II (Nodes 400 to 410). Neutron flux and power distributions calculations for each of the PB, FSV, and HITREX II critical assembly, as described above, will be repeated using the current neutron cross sections and methods. These calculations will be compared to the measured data and the comparison will be documented. Previous comparisons will also be documented, as required.

4.3.2.2. VHTRC (Nodes 415 to 450). JAERI has performed a series of flux distribution measurements in their VHTRC assembly at $20^{\circ}$ and $200^{\circ} \mathrm{C}$ $\left(68^{\circ}\right.$ and $\left.392^{\circ} \mathrm{F}\right)$, using $2 \%$ and $4 \%$ LEU fuel. Proposals have been made to obtain these data. Comparisons will be made of these data and GA calculations. Comparisons of calculations and JAERI calculations will also be made and all these comparisons will be documented.

\subsubsection{CNPS (Nodes 415 to 450). A plan is being developed (along} with (TDN update) for a series of flux distribution measurements in the CNPS critical facility. Calculations will be done and compared to these measured data and to the Los Alamos calculations and all comparisons will be documented.

\subsection{CORE CRITICALITY AND MATERIAL REACTIVITY WORTH}

The verification of the codes used in the calculational method for core criticality and for material reactivity worth is discussed in Section 4.7 . 


\subsubsection{Validation Status}

The core criticality calculational method has been previously validated for HEU fuels using comparisons of measured and calculated data from PB, HTGR critical, and FSV (Refs. 30 and 39). In all cases, the measured and calculated criticality agreed when $\leq 0.50 \% \Delta \rho$.

Material reactivity worths ( $B, U, T h$, etc.) have been calculated and compared to measured data from the PB and HTGR criticals. In these comparisuns, the agrement was within $\pm 10 \%$.

\subsubsection{Validation P1az}

The specific experiments which will be used for the validation of the methods for calculating the MHTGR core criticality and material reactivity worth are described in this section. The schedule for this work is given in Chapter 5, Figs. 5-1 and 5-5.

\subsubsection{PB, HTGR Critical, and FSV (Nodes 800 to 825). Criticality} calculations for each of the PB, HTGR critical, ESV, and material reactivity worths for the PB and HTGR critical will be repeated using the current neutron cross sections and methods. Comparison of these calculations with the asured data will justify the use of the previous comparisons in this program. These comparisons w111 be documented. Previous comparisons will also be documented, as required.

\subsubsection{AVR (Nodes 800 to 815). AVR criticality measurements have been made throughout the burnup cycle as LEU is added to the core. Calculations will be made and compared to these measurements and these comparisons 111 be documented. In addition, plutonium production mea- surements have been made on LEU fueled pebbles irradiated in a single pass through the AVR core. These measurements will be compared to predictions made with GA methods, and the results documented.}


4.4.2.3. VHTRC (Nodes 830 to 860 ). Proposals have been made to obtain clean critical and material reactivity worth measured data from the VHTRC experiment. It is also proposed that a series of criticality measurements be made with a central column of MHTGR fuel elements using $20 \%$ enriched fuel, and that the Pu-239/U-235 fission ratio and U-238/ 0-235 capture to fission ratio be measured. Each of these parameters wil be calculated and compared to the measured data and to the JAERI calculations. All comparisons will be documented.

4.4.2.4. CNPS (Nodes 830 to 860). Criticality measurements have been made in the CNPS core. Calculations will be made and compared to both the measurements and to LASL calculations. A11 comparisons will be documented.

\subsection{WATER INGRESS EFFECTS}

The verification of the codes used in the calculational method for the MHTGR water ingress effects is discussed in Section 4.7.

\subsubsection{Validation Status}

The methods used to calculate the water ingress effects have not previously been validated. The validation will be done as a part of this program.

\subsubsection{Validation Plan}

Data from the following experiments will be used to validate the methods for calculating the MHTGR water ingress effects. The schedule for this work is given in section 5, Figs. 5-1 5-6.

4.5.2.1. PB Critical (Nodes 300 to 320). A series of measurements were made in the $P B$ critical assembly to evaluate the reactivity effect of water. The first series of measurement evaluate wet versus dry graphite 
by placing samples in the central position of the core. For the drygraphite measurement, reflector material was used that had been heated to $260^{\circ} \mathrm{C}\left(500^{\circ} \mathrm{F}\right)$. The result was then compared with graphite which was deliberately soaked in water.

A second sèries of measurements were made in which strips of polyethylene were placed at various positions in the core to simulate water. A distributed reactivity coefficient of polyethylene was measured, as well as a reactivity coefficient for the polyethylene distributed axially in the central position. Also, the worth of polyethylene was measured in the reflector at a position midway radially through the reflector midplane.

Calculations will be done and compared to these measured data and all comparisons will be documented.

4.5.2.2. CNPS Critical (Nodes 300 to 340). A serles of measurements are being considered for the CNPS critical to determine the reactivity effect of varying amounts and distributions of water. These measurements will be made by addition of polystyrene to the core and/or the reflector to simulate water. Calculations will be performed and compared to both the measured data and to the LASL calculations. All of these comparisons will be documented. A TDN update is planned to include this work.

\subsubsection{IFA Subcritical (Nodes 300 to 340). A series of subcritical} experiments were performed by Kernforschungsanlage (KFA) in which water ingress into systems with pebble-bed HTGR fuel was simulated (Ref. 40). Experiments with six different concentrations of polyethylene, with a water equivalency between $0 \%$ and $14.4 \%$ volume in the active core, were performed.

Calculations will be performed and compared to the measured results and to the KFA calculations and these comparisons will be documented. 
4.6. DECAY HEAT PRODUCTION - "ै

The verification of the GARGOYLE and MICROX codes used in the calculational method for decay heat production is discussed in Section 4.7.

\subsubsection{Validation Status}

The methods used to calculate the decay heat production have not previously been validated. The validation will be done as a part of this program. The schedule for this work is given in Section 5, Figs. 5-1 and 5-7.

\subsubsection{Validation Plan}

Decay heat production measurements applicable to LWR have been made (Refs. 16 and 41). In adition, decay heat data with direct applicability to the MHTGR may become available from the AVR test program. All these data will be utilized for the validation program. (Nodes 500 to 520 and 530 to 540 .)

Decay heat calculations will be performed and compared to the ANSI standard (Ref. 16). Calculations will also be done and compared to the AVR measured data. All comparisons will be documented. In addition, GA calculations will be compared to calculations done using the ORIGEN, CINDER, and/Or RIBD codes. (Nodes 550 to 560.)

\subsection{CODE VERIFICATION}

As discussed in Section 1.3.5, a verification procedure was performed on the computer programs used for MHTGR physics calculations prior to use as standard production codes. This verification was updated if any modification was made to the codes. A list of the physics codes which are relevant to this validation program is given in Table 4-2. 
TABLE $4-2$

IIST OF PHYSICS COMPUTER CODES

USED FOR MHTGR ANALYSIS

DTFX

FEVER

TEMCO

GAUGE

$2 D B$

GARGOYLE

BLOOST

MICROX 
The verification procedure consisted of the following steps performed by the programer:

- Review of coding for conformity with good programing practice.

- Review of the code for completeness, correctness, and consistency.

- Operation of the code to obtain the solutions to a series of test problems to demonstrate that these are substantially identical to those obtained by hand calculations or from accepted experimental tests or analytical results published in technical 1iterature, or the results obtained from an independenty developed program.

- Document the code as to applicability, models used, Iimitations, input instructions, output examples, etc.

In addition, an independent review of this code verification was performed, which included:

1. A review of the program for applicability to the physical model and/or a review of the mathematical model for correctness.

2. A determination that sample/test problems have been run and are available and that the results have been evaluated and documented.

3. Documentation of the independent review including the method used, the extent to which verification has been satisfactorily accomplished. 
Each modification to the code was verified by running test problems and checking that no changes had been introduced into the unmodified portions of the program. This verification was documented.

For the codes listed in Table $4-2$, the verification work will be reviewed, updated as necessary to meet the requirements discussed in Section 2, and the documentation incorporated into the V\&V report for MHTGR physics methods. The sample problems will also be reviewed for appliciblity to MHTGR conditions, and additional test problems run if necessary. If the validation program requires modification to these codes, the verification will be updated as necessary. 


\section{SCHEDULE AND COST ESTIMATES}

The overall schedule for the core physics methods VSV plan, consistent with the 5-year NIE program, is given in Fig. 5-1. More detailed schedules for each V\&V area are given in Figs. 5-2 through 5-7.

A preliminary cost estimate sumary for this program is given in Table 5-1, more detailed breakdowns following the detailed schedules are given in Table 5-2, 


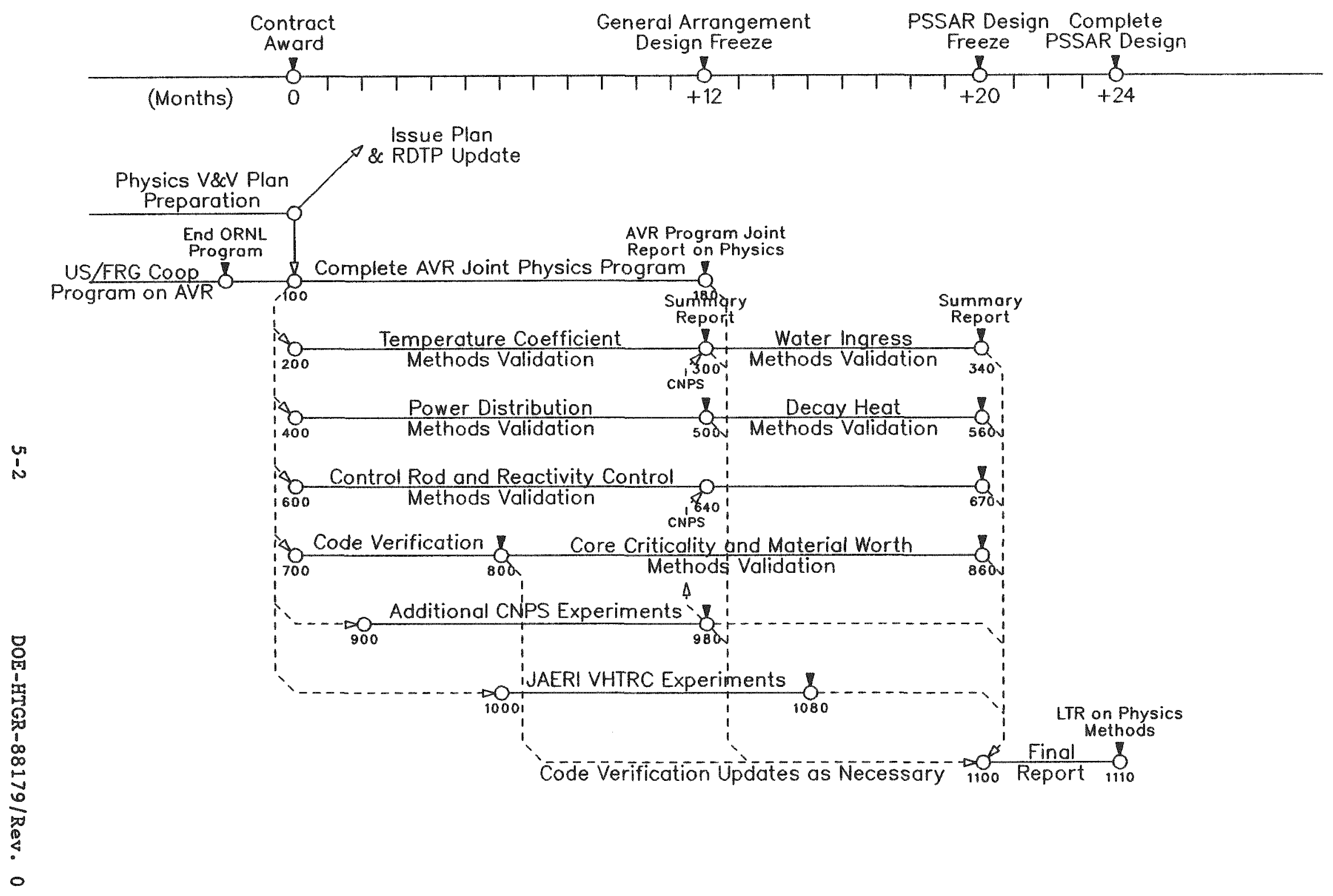

Fig. 5-1 Overall Physics Validation and Verification Schedule 


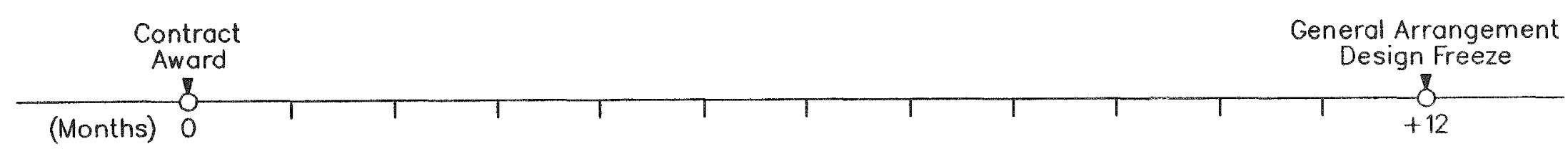

Calculate AVR

Temperature Coefficients

and Compare

8

$\longrightarrow \underset{290}{\longrightarrow} \quad$ Temperature Coefficients

Recalculate and/or Document

Critical Measurements,

$220 \quad$ Operating Data.

and HTLTR Experiments

Calculate

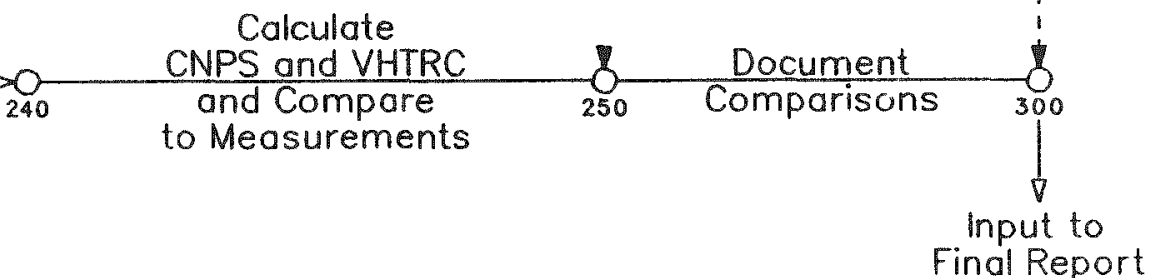

8
8
01
1
1
0
0
0
1
0
0
0
1
0
0
0
0
4
0
0

Fig. 5-2 Temperature Coefficient Methods Validation Schedule 


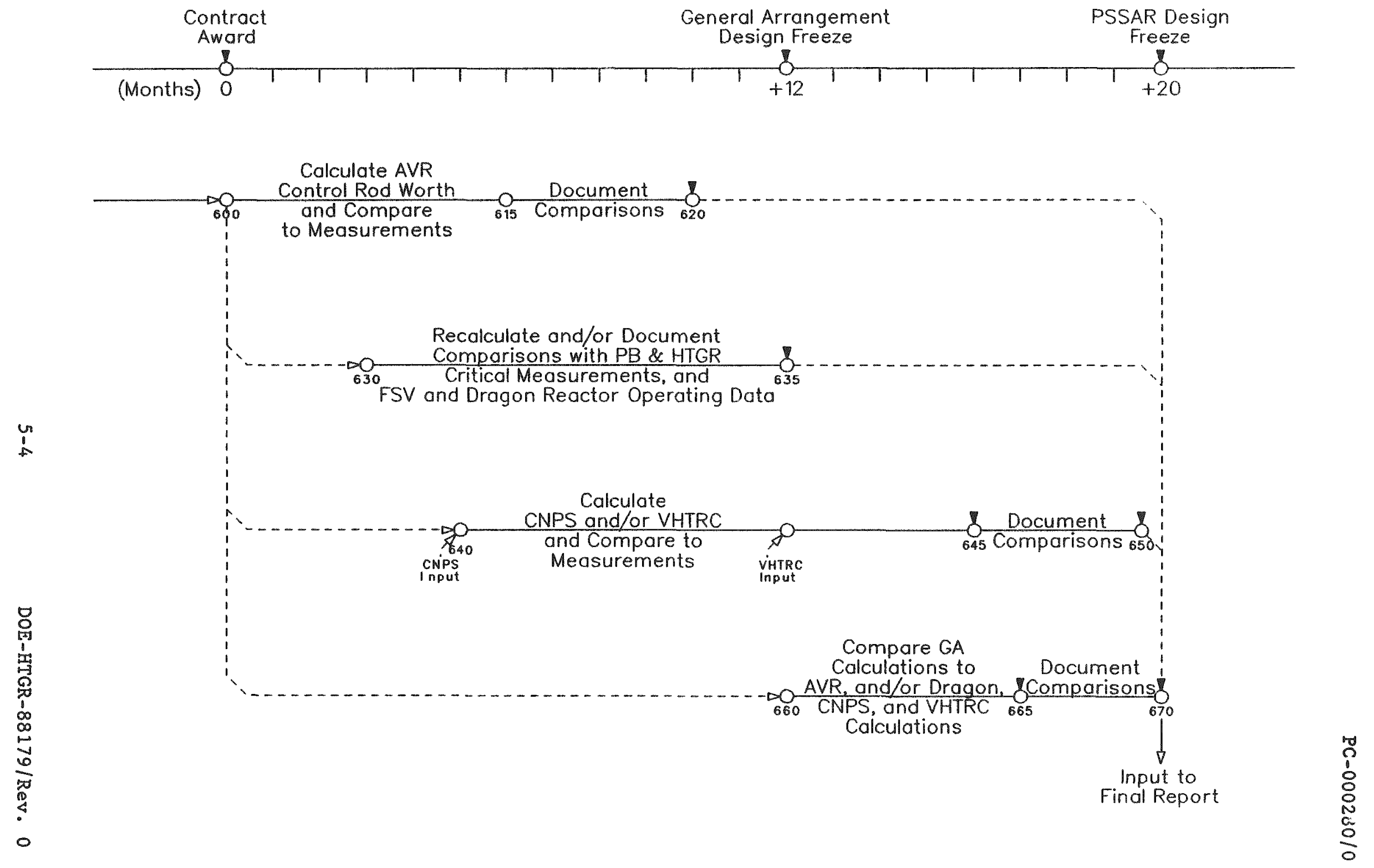

Fig. 5-3 Control Rod and Reactivity Worth Methods Validation Schedule 


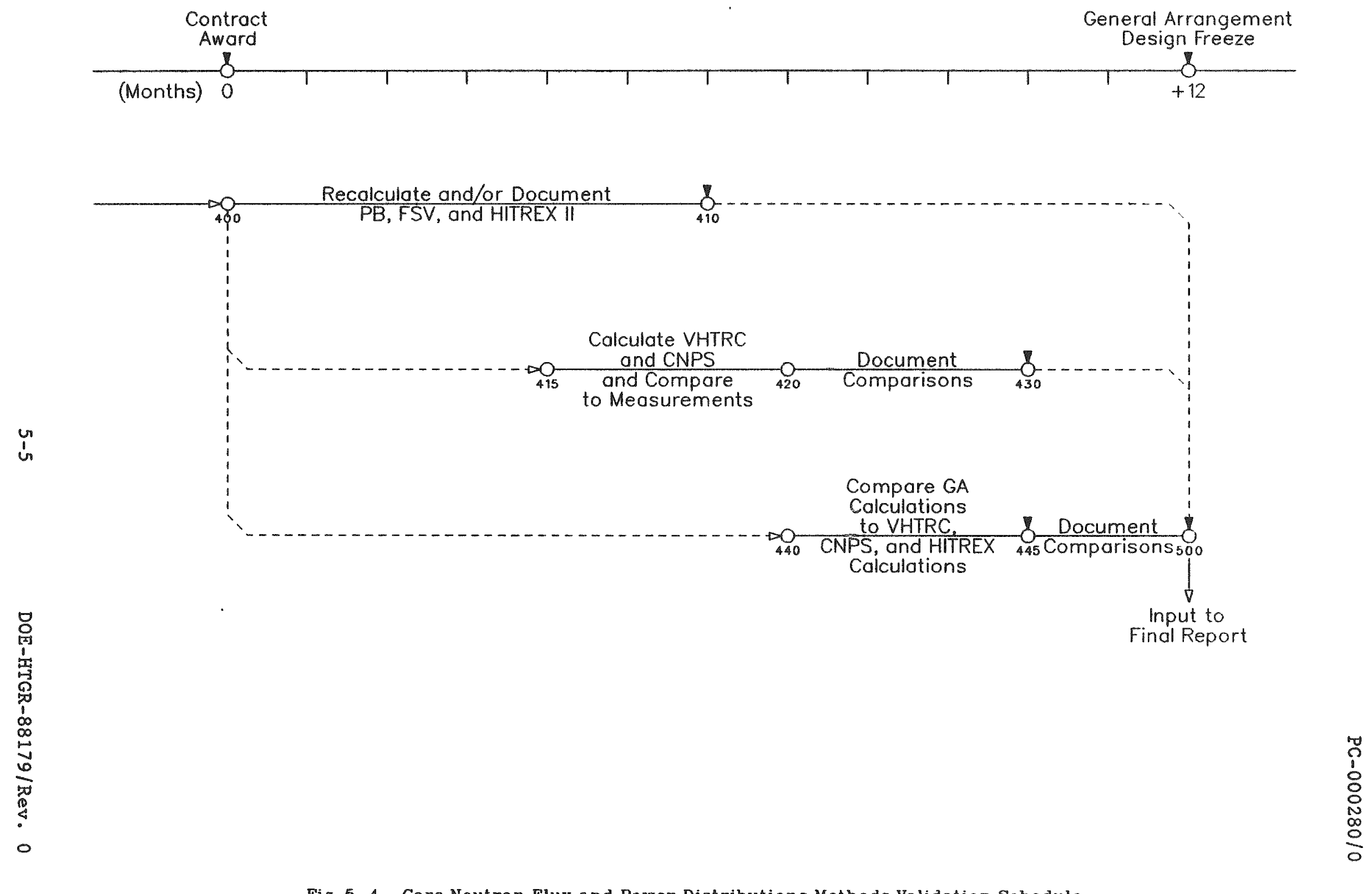

Fig. 5-4 Core Neutron Flux and Power Distributions Methods Validation Schedule 


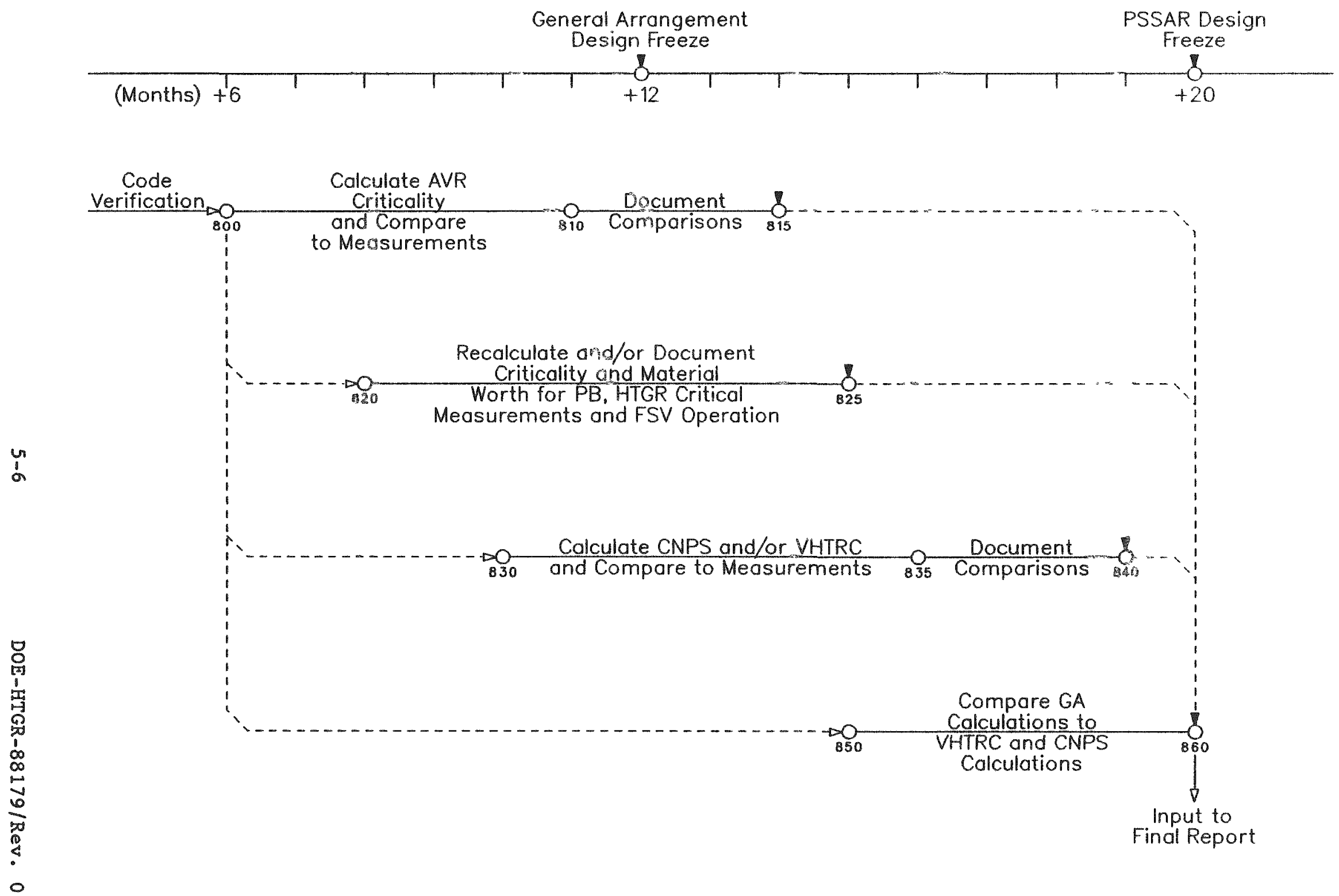

Fig. 5-5 Core Criticality and Material Reactivity Worth Methods Validation Schedule 


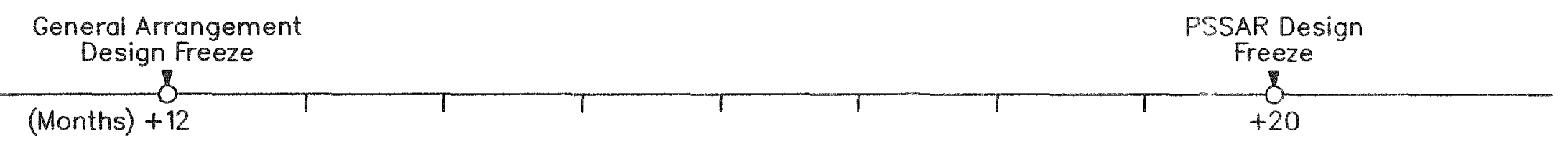

Calculate PB Critical

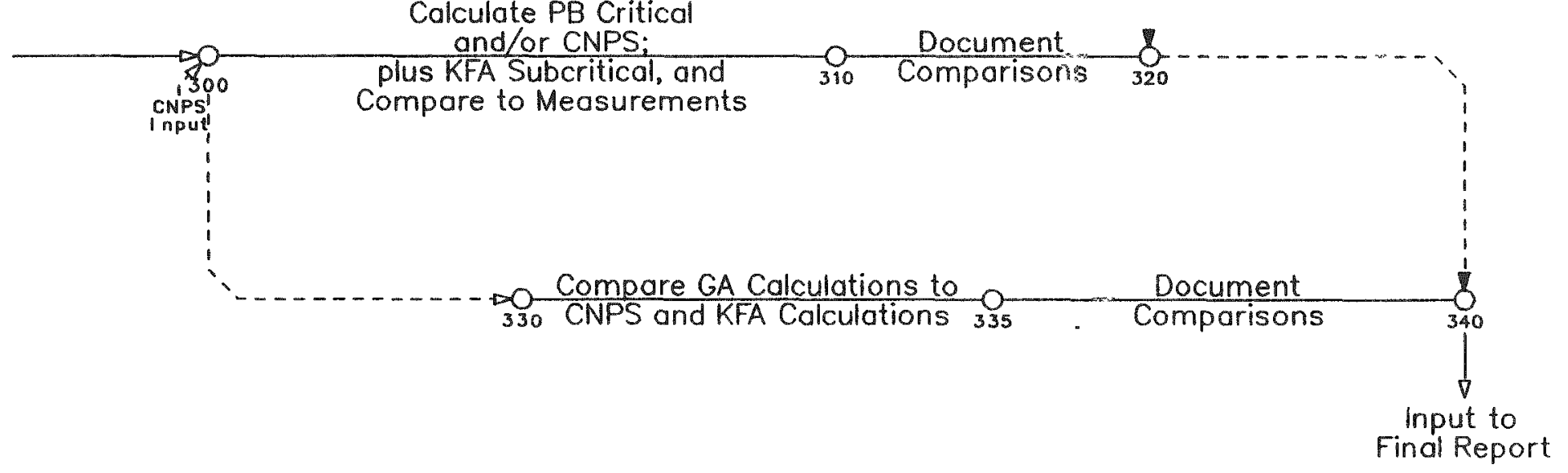

Fig. 5-6 Water Ingress Reactivity Worth Methods Validation Schedule 


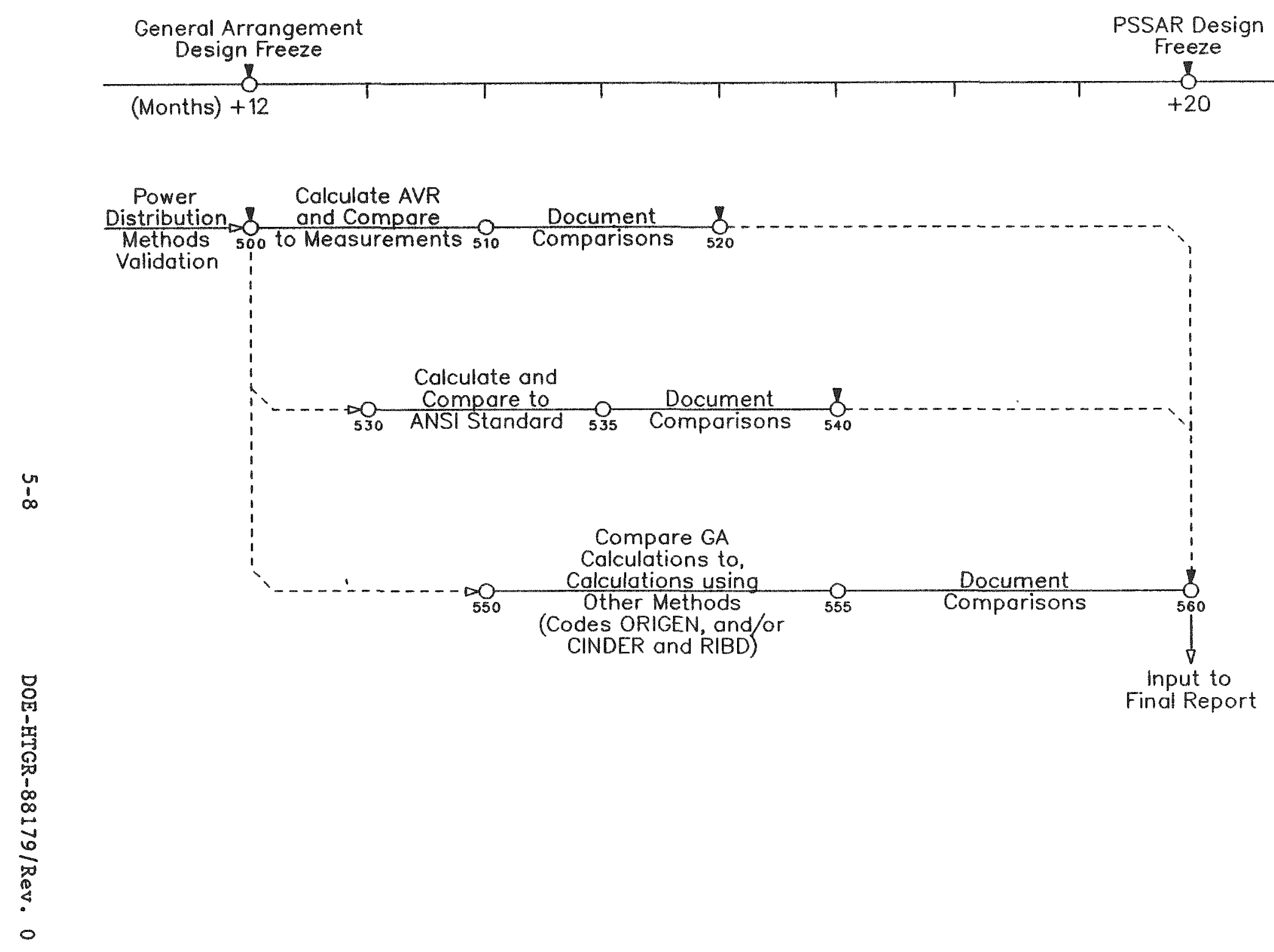


TABLE 5-1

COST SUMMARY FOR VALIDATION PROGRAM

\begin{tabular}{lc}
\hline \multicolumn{1}{c}{ Item } & $\$(1000 \mathrm{~s})$ \\
\hline Code verification & 100 \\
Temperature coefficient methods validation & 400 \\
Control rod reactivity worth methods validation & 300 \\
Core neutron flux and power distribution methods & 230 \\
validation & \\
Core criticality and material reactivity worth & 240 \\
methods validation & \\
Water ingress reactivity worth methods validation & 250 \\
Decay heat methods validation & 240 \\
Preparation of final report & 100 \\
Perform CNPS experiments & 250 \\
Monitor vHTRC experiments & 90 \\
Total & 2200 \\
\hline
\end{tabular}


PC $-000280 / 0$

TABLE 5-2

COST BREAKDOWN FOR VALIDATION PROGRAM

\begin{tabular}{|c|c|c|}
\hline Item & Node Nos. & $\$(1000 s)$ \\
\hline \multicolumn{3}{|l|}{ Temperature Coefficient Methods Validation } \\
\hline - AVR temperature coefficient comparisons & $299-210$ & 65 \\
\hline - $P B$ and HTGR critical experiments & $220-230$ & 80 \\
\hline - PB and FSV operation, and HTLTR experiment & $220-230$ & 125 \\
\hline - CNPS and VHTRC comparisons & $240-260$ & 105 \\
\hline - Documentation & A11 & 25 \\
\hline \multicolumn{3}{|l|}{ Control Rod Reactivity Worth Methods Validation } \\
\hline - AVR rod worth comparisons & $600-620$ & 30 \\
\hline - $P B$ and HTGR critical experiment & $630-635$ & 35 \\
\hline - FSV and dragon operating data & $630-635$ & 105 \\
\hline - CNPS and VHTRC experiments & $640-650$ & 65 \\
\hline - Comparison with other methods & $660-670$ & 40 \\
\hline - Documentation & A11 & 25 \\
\hline \multicolumn{3}{|l|}{ Core Power Distribution Validation } \\
\hline - PB, FSV, and HITREX-II comparisons & $400-410$ & 95 \\
\hline - CNPS and VHTRC measurements & $415-430$ & 70 \\
\hline - Comparison with other methods & $440-450$ & 40 \\
\hline - Documentation & A11 & 25 \\
\hline \multicolumn{3}{|l|}{ Core Criticality and Material Worth Validation } \\
\hline - AVR measurement comparisons & $800-815$ & 50 \\
\hline - HTGR criticals & $810-825$ & 40 \\
\hline - $\mathrm{PB}$ and FSV operation & $820-825$ & 50 \\
\hline - CNPS and VHTRC measurements & $830-840$ & 50 \\
\hline - Comparison with other methods & $850-860$ & 30 \\
\hline - Documentation & A11 & 20 \\
\hline \multicolumn{3}{|l|}{ Water Ingress Methods Validation } \\
\hline - $\mathrm{PB}$ critical experiments & $300-320$ & 65 \\
\hline - CNPS measurements & $300-320$ & 85 \\
\hline - KFA subcritical measurements & $300-320$ & 35 \\
\hline - Comparison with other methods & $330-340$ & 40 \\
\hline - Documentation & A11 & 25 \\
\hline \multicolumn{3}{|l|}{ Decay Heat Methods Validation } \\
\hline - AVR measurement comparisons & $500-520$ & 65 \\
\hline - ANSI standard comparisons & $530-540$ & 50 \\
\hline - Comparison with other methods & $550-560$ & 95 \\
\hline - Documentation & A11 & 30 \\
\hline
\end{tabular}


TABLE 5-2 (Continued)

\begin{tabular}{|c|c|c|}
\hline Item & Node Nos. & $\$(1000 s)$ \\
\hline \multicolumn{3}{|l|}{ Code Verification } \\
\hline $\begin{array}{l}\text { - Review code verification work and documenta- } \\
\text { tion, update as necessary } \\
\text { - Update code verification as necessary during } \\
\text { methods validation program }\end{array}$ & $\begin{array}{l}700-800 \\
800-1100\end{array}$ & $\begin{array}{l}70 \\
30\end{array}$ \\
\hline Additional CNPS Experiments & & \\
\hline $\begin{array}{l}\text { - Perform reflector control rod worth } \\
\text { measurements }\end{array}$ & $900-980$ & 100 \\
\hline $\begin{array}{l}\text { - Perform water worth measurements } \\
\text { - Measurement predictions, analysis, and } \\
\text { support }\end{array}$ & $\begin{array}{l}900-980 \\
900-980\end{array}$ & $\begin{array}{r}100 \\
50\end{array}$ \\
\hline $\begin{array}{l}\text { Monitor VHTRC Experiments } \\
\text { Interact with VHTRC personnel to ensure } \\
\text { that proposed control rod worth and criticality } \\
\text { measurements are correctly performed. Provide } \\
\text { support analysis and documentation as required }\end{array}$ & $1000-1090$ & 90 \\
\hline
\end{tabular}


PC $-000280 / 0$

\section{REFERENCES}

1. "MHTG" Core Nuclear and Fuel Performance Conceptual Design," DOEHTGR-87-063/Rev. O (GA Document 909468/0), July 1987.

2. "MHTGR Core Nuclear Sensitivity Analyses," DOE-HTGR-87-085/Rev. 2 (GA Document 909508/2), November 1987.

3. "Overall Plant Design Specification Modular High-Temperature GasCooled Reactor," DOR-HTGR-86004, Rev. 3 (DOE-HTGR-86-00413) (RGE 908397/3), October 1986.

4. "Physics Code Validarion Plan - Part I," PC-000268/0, December 1987.

5. Cleveland, J. C., A. M. Baxter, and K. Krueger, "Subprogram Plan for Cooperation in AVR Test Program," DOE-HTGR-88094, October 1987.

6. "Functional Analysis Report - Standard Modular HTGR Plant," DOE-HTGR-86-002/Rev. 2 (PC-000207/2), Vols. 1 to 3, February 1987.

7. "American National Standard for Quality Assurance Program Requirements for Nuclear Feilities," ANSI/ASME NQA-1-1986 (including supplements 3S-1, 11S-2, and Appendix 3A-1).

8. "American National Standard: Guidelines for the Verification and Validation of Scientific and Engineering Computer Programs for the Nuclear Industry, "ANSI/ANS-10.4-1987, American Nuclear Society, La Grange Park, I11inois, May 1987.

9. American National Standard: Guidelines for the Documentation of Digital Computer Progzans," ANSI/ANS-10.3-1986, American Nuclear Soclety, La Grange Park, IIlinois, 1986.

10. "American National Standard: Nuclear Data Sets for Reactor Design Calculations," ANSI/ANS-19.1-1983, American Nuclear Society, La Grange Park, Illino1s, July 1983.

11. "American National Standard: Determination of Neutron Reaction Rate Distrfbutions and Reactivity of Nuclear Reactors," ANSI/ ANS-19.3-1983, American Nuclear Society, La Grange Park, I1Iinois, June 1983. 
12. "American National Standard: Determination of Thermal Energy Deposition Rates in Nuclear Reactors," ANSI N676/ANS-19.3.4-1983 (Reafimation of ANSI N676-1976/ANS-19.3.4, June 1976), American Nuclear Society, La Grange Park, I1linois, June 1983.

13. "American National Standard: Acquisition and Documentation of Reference Power Reactor Physics Measurements for Nuclear Analysis Verification," ANSI N652/ANS-19.4-1983 (Reaffirmation of ANS-19.4/ANSI N652-1976, June 1976), American Nuclear Society, La Grange Park, Illinois, June 1983.

14. "American National Standard: Requirements for Reference Reactor Physics Measurements," ANSI/ANS-19.5-1984 (Reaffirmation of ANSI/ ANS-19.5-1978, November 1978), American Nuclear Society, La Grange Park, Illinois, May 1984.

15. "American National Standard Quality Assurance Requirements for Nuclear Power Plants - Part 2.7," ANSI/ASME NQA-2-1983.

16. "American National Standard: Decay Heat Power in Light-Water Reactors," ANSI/ANS-5.1-1979, American Nuclear Society, La Grange Park, I11inois, August 1979.

17. "Domestic Iicensing of Production and Utilization Facilities," U.S. Nuclear Regulatory Comission, Code of Federal Regulations, 10CFR Part 50, Appendix B (Quality Assurance Criteria for Nuclear Power Plants and Fuel Reprocessing Plants), September 28, 1984.

18. "Quality Assurance Requirements for the Design of Nuclear Power Plants," U.S. Nuclear Regulatory Comission, Regulatory Guide 1.64, Rev. 2, June 1976.

19. "Quality Assurance Program Requirements - Design and Construction," Regulatory Guide 1.28, Rev. 3, August 1985.

20. "Quality Assurance Program Requirements for Nuclear Facilities," ANSI/ASME NQA-1-1983, 1983 Edition.

21. "Final Technical Position on Documentation of Computer Codes for High-Level Waste Management," U.S. Nuclear Regulatory Commission, NUREG-0856-F, June 1983.

22. "Initial Test Programs for Water-Cooled Reactor Power Plants," Regulatory Guide 1.68, Rev. 2, August 1978. 
23. "USNRC Standard Review Plan," NUREG-0800, Rev. 2, Section 4.3, JuIy 1981.

24. "Standard Format and Content of Safety Analysis Reports for Nuclear Power Plants - IWR Edition," Regulatory Guide 1.70, Rev. 3, November 1978.

25. "Handbook of Software Quality Assurance Techniques Applicable to the Nuclear Industry," NUREG/CR4640 (PNL-5784), August 1987.

26. Oaks, T. J., "Measurement of the Neutron Multiplication Factor as a Function of Temperature for a $235 \mathrm{UC}_{2}-232 \mathrm{ThO}_{2}-\mathrm{C}$ Lattice," BNWL-SA3621 (undated - approximately January 1971).

27. Newman, D. F., "Temperature-Dependent $\mathrm{K}_{\infty}$ for a $\mathrm{ThO}_{2}-\mathrm{PuO}_{2} \mathrm{HTGR}$ Lattice," Nuclear Technology 19, August 1973.

28. Schultz, K. R., and D. R. Mathews, "General Atomic Participation in the High-Temperature Lattice Test Reactor Program,"GA-A12710, March 1976.

29. Pohl, P., et al., "Determination of the Hot- and Cold-Temperature Coefficient of Reactivity in the AVR Core," Nuclear Science and Engineering, 97, pp. 64-71 (1987).

30. Brown, J. R., et al., "Physics Testing at Fort St. Vrain - A Review," Nuclear Science and Englneering, 97, pp. 104-122 (1987).

31. Drïke, V., and D. Filges, "The Critical HTGR Test Facility KAHTER An Experimental Program for the Verification of Theoretical Models, Codes, and Nuclear Data Bases," Nuclear Science and Engineering, 97. Pp. 30-36 (1987).

32. Drüke, V., et a1., "Experiments on Inhomogeneous Fuel Loading at the Critical HTGR Test Facility KAHTER: A Study for the Future Loading Concept of Pebble-Bed Reactors," Nuclear Science and Engineering, 97, pp. 37-52 (1987).

33. DeIla Loggia, V. E., et a1., "Measurements of Control Rod Worth and Excess Reactivity on the First Core of DRAGON," DP-Report-359, Dragon Project, Atomic Energy Establishment, Winfrith, England, July 1965. 
34. Della Loggia, V. E., C. Hung, and W. H. Taylor, "Zero Energy Experiments on the DRAGON Reactor Prior to Charge IV Startup," DP-Report-820, Dragon Project, Atomic Energy Establishment, Winfrith, England, January 1973.

35. Marshal1, A. C., and J. R. Brown, "Neutron Flux Distribution Measurements in the Fort St. Vrain Initial Core," GA-A13176, February 28, 1975.

36. Waterson, R. H., "The BNL MARK-III Reactor HITREX - Physics Information," RD/B/M2208, RPC/RPNK/P(76)8, Apri1 1976.

37. Kitching, S. J., et al., "Physics Measurements on the Zero-Energy Reactor HITREX-2 Incorporating an Integral Block Fuel Zone Description of the Programe and Stage 1 Measurements on the Basic Lattices," RD/B/N3979, January 1978.

38. McKechnie, A. J., "An Analysis of Reactor Physics Experiments on the Basic Lattice of the BNL Reactor HITREX-2," RD/B/N4580, June 1979 .

39. Bardes, R. G., et al., "Results of the HTGR Critical Experiments Designed to Make Integral Checks on the Cross Sections in Use at Gulf General Atomic," GA-8468, February 12, 1968.

40. Drüke, V., et al., "Experimental and Theoretical Studies of Criticality Safety by Ingress of Water in Systems With Pebble Bed HighTemperature Gas-Cooled Reactor Fuel," Nuclear Sclence and Engineering, 57, pp. 328-332 (1975).

41. Dickens, J. K., "Current Status of Decay Heat Measurements, Evaluations, and Needs," ORNL/TM-10094, July 1986. 


\section{APPENDIX A}

A brief description of the experimental facilities, in which core physics measurements were made, is given in this appendix. These include:

- Peach Bottom Critical

- Peach Bottom Reactor

- hTGR Critical

- FSV Reactor

- HTLTR

- AVR

- VHTRC

- CNPS Critical

- Dragon Reactor

- HITREX

- kAHTER

- MaRTUS

\section{A.1. PEACH BOTTOM CRITICAI}

The Peach Bottom critical assembly was constructed to evaluate the accuracy of calculational techniques for the Peach Bottom core. [Peach Bottom was a 115 MW(t) high-temperature, graphite-moderated, helium-cooled HTGR.]

This critical assembly was constructed in two separable halves (a fixed half, and a movable half), each with its own control rods (four, two in each half), located along longitudinal axes at the corereflector interface $180 \mathrm{deg}$ apart (see Fig. A.1). In addition, four critical-assembly safety rods were positioned around the core. 
PC- $-000280 / 0$

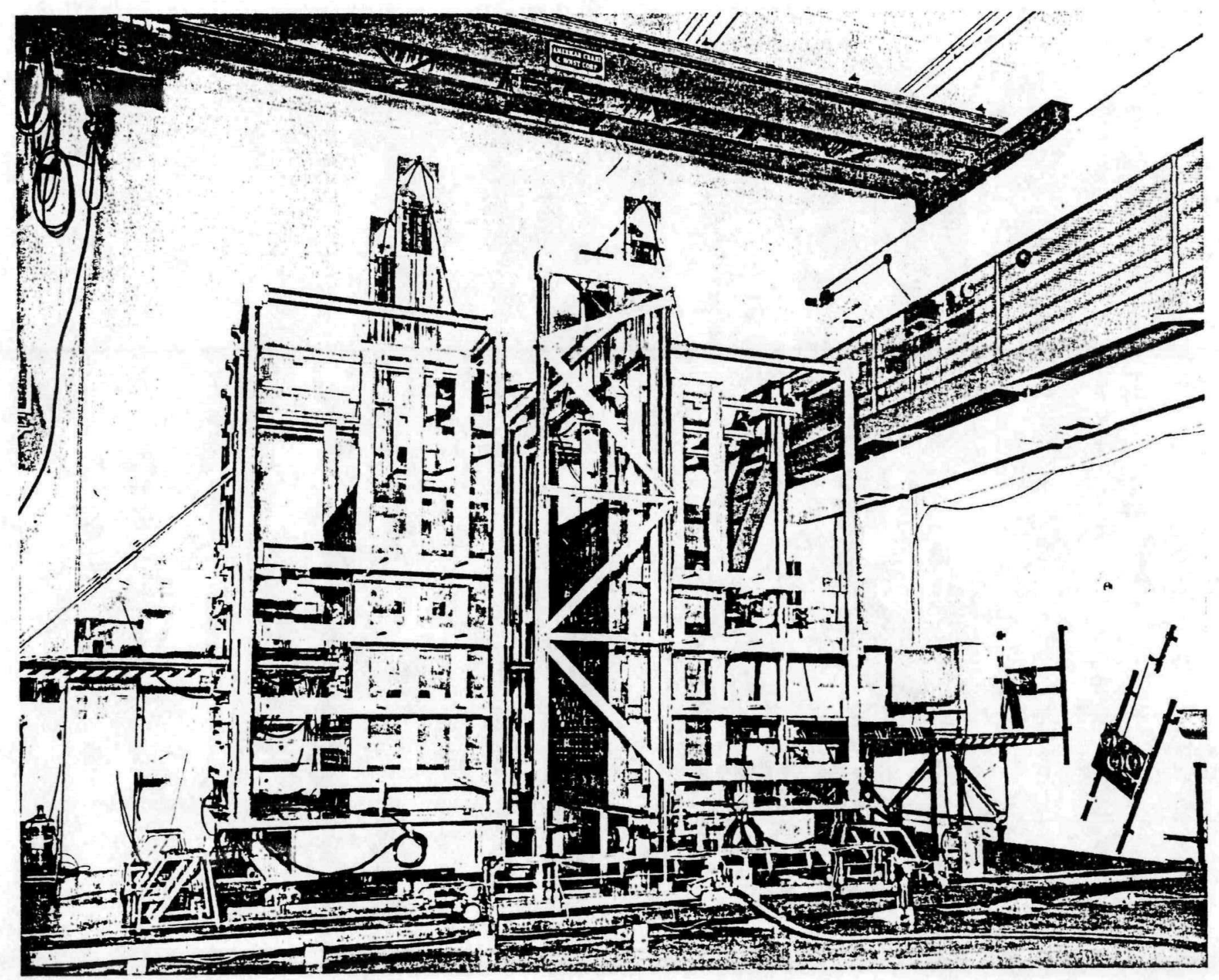

Fig. A-1. Overall view of Peach Bottom HTGR critical assembly 
The critical assembly, which had a volume about one-sixth that of the Peach Bottom reactor core, was a horizontal "cylinder" about $1.5 \mathrm{~m}$ $(5 \mathrm{ft})$ in diameter and $1.2 \mathrm{-m}(4-\mathrm{ft})$ long, separable at the vertical midplane. The critical-assembly core was completely reflected with about $0.61 \mathrm{~m}$ (2 ft) of graphite, and contained 19 holes, or voids, simulating Peach Bottom HTGR control-rod positions (see Fig. A-1, which is a photograph of the vertical midplane of the assembly with the halves of the assembly separated). Each of these holes was a 101-m (4-in.) square, running the full 1.2-m (48-in.) length of the core. The "fuel elements" consisted of rectangular graphite blocks that contained cylindrical compacts of either a fully enriched uranium-graphite mixture or of a thorium-graphite mixture.

The experimental program was conducted during 1959 through 1962.

\section{A.2. PEACH BOTTOM REACTOR}

The Peach Bottom Nuclear Generating Station, designed by GA and owned and operated by the Philadelphia Electric Company, was the first HTGR in the United States. This demonstration high-temperature, graphite-moderated, gas-cooled reactor was designed to produce $115 \mathrm{MW}(t)$ at an average power density of $8.3 \mathrm{MW}(t) / \mathrm{m}^{3}$.

The active core of the Peach Bottom reactor was approximately cylindrical in shape with an effective diameter of approximately $2.7 \mathrm{~m}$ (9 ft) and a height of approximately $2.3 \mathrm{~m}(7.5 \mathrm{ft})$. The core was surrounded by a graphite reflector approximately $0.61-\mathrm{m}$ (2-ft) thick on the top and sides, and approximately $0.76-\mathrm{m}(2.5-\mathrm{ft})$ thick on the bottom (see Fig. $A-2$ ). The core was made up of 804 individual fuel elements, each of which is a cylinder $3.7-\mathrm{m}(12-\mathrm{ft})$ long and 89 (3.5 In.) in diameter. The fuel elements were supported by a metal support plate and oriented vertically in a closely packed triangular array. The helium coolant flowed upward through the spaces between the closely packed elements into the plenum above the active core. The fuel cycle used 


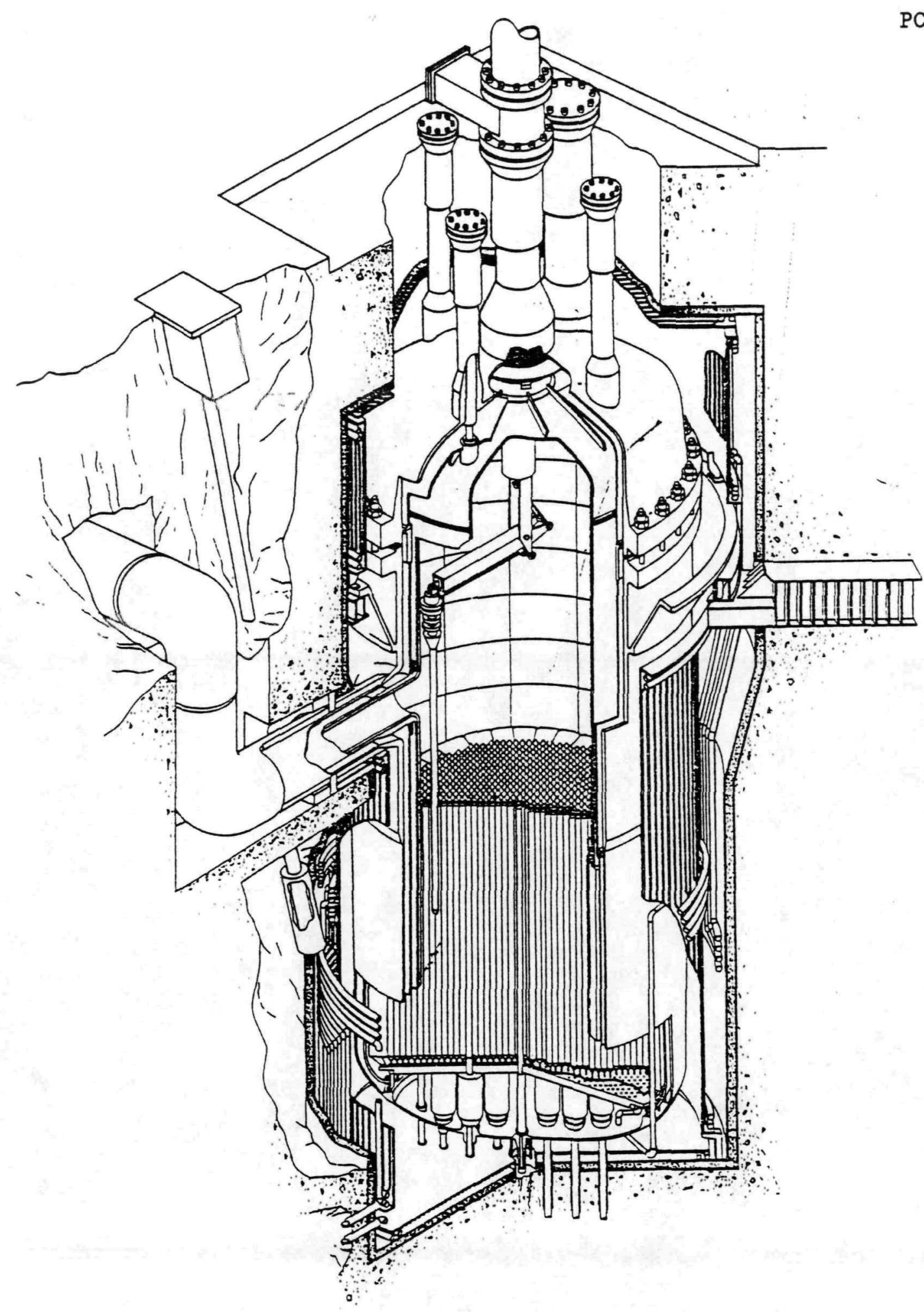

PC- $000280 / 0$ 
fully enriched U-235 as the initial fissile material and Th-232 as the fertile material, and contained in cylindrical rod-type graphite fuel elements.

Thirty-six control rods were provlded to serve normal control functions. The absorber material was boron carbide in a graphite matrix, and the control rods move within graphite guide tubes. The outer diameter of the guide tubes was the same as the diameter of the fuel elements.

In addition to the normal control rods, an independent backup shutdown system was provided, consisting of a group of 19 electrically driven emergency shutdown rods.

The reactor operated successfully from 1967 to 1975 , at which time it was permanently shut down.

\section{A.3. HTGR CRITICAL}

The HTGR critical, operated at GA from 1966 through 1969, was used to test those features that differed significantly from Peach Bottom; i.e., higher $\mathrm{C} / \mathrm{U}$ ratio, a different fuel element, control rod, and lumped burnable poison design.

The critical assembly consisted of an array of 42-mm (1.66-in.) o.d. aluminum tubes welded Into a honeycomb structure into which core and reflector materials could be located, and was mounted on a split bed assembIy machine as shown in Fig. A-3. The assembly machine and much of the fuel from the earlier Peach Bottom critical assemblies were used. Each half of the honeycomb was approximately $2.1-m(7-f t)$ square by $0.91-m(3-f t)$ long, so that when the bed was fully closed a honeycomb $2.1 \mathrm{~m}(7 \mathrm{ft})$ by $2.1 \mathrm{~m}$ (7 ft) by $1.8 \mathrm{~m}(6 \mathrm{ft}$ ) was obtained. For all of the experiments in which lattice fuel elements (HTGR mock-up) are used, 


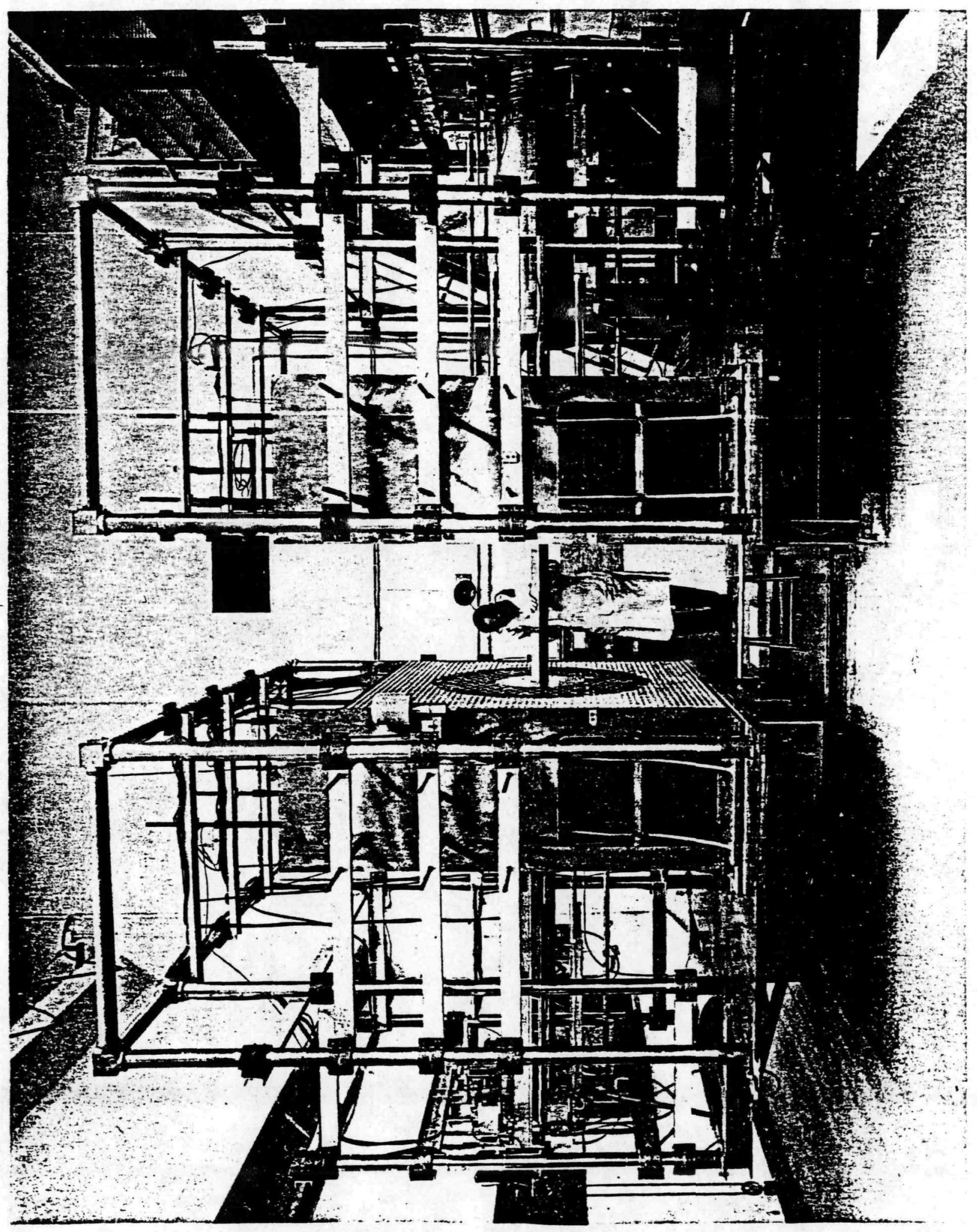

Fig. A-3. Side view of HTGR critical Lattice 2 core assembly 
the honeycomb assembled was modified by removing the central 193 aluminum tubes in each half and replacing them with hexagonal elements. These elements were $0.90-\mathrm{m}\left(35.5-i n_{0}\right)$ long and 115 (4.55 in.) across the wats and have $11.4 \mathrm{~m}$ was $\left(0.450-1 \mathrm{n}^{\circ}\right)$ diameter holes bored on a $19.0 \mathrm{~mm}$ $\left(0.750-i n_{0}\right)$ pitch.

In the core assembly (honeycomb) surwounding the central lattice, Euel lements consisting of high enriched uranium-graphite compacts contained in thin-walled aluminum tubes were located.

Eight horizontal safery rods and four horizontal control rods, as well as bed separation, provlded reactivity control in the critical assembly.

\section{A.4. FORT ST. VRAIN REACTOR}

The Fort St. Vrain (FSV) Nuclear Generating Station, designed and built by GA, and owned and operated by Public Service Company of Colorado (PSC), is a plant employing the high-temperature gas-cooled reactor (IETGR) concept. The plant was designed to produce $842 \mathrm{MW}(\mathrm{t})$ and $330 \mathrm{MW}(e)$ at an average power densicy of $6.3 \mathrm{MW}(t) / \mathrm{m}^{3}$.

The active core of the reactor is approximately a right circular cylinder with an equivalent diameter of about $5.9 \mathrm{~m}(19.5 \mathrm{ft})$ and a vertical height of approximately $4.8 \mathrm{~m}$ (15.6 ft). vertical view of a section of the core assembly is shown in Fig. A-4. The core is surrounded by graphite reflectors, which have an effective thickness of $1.0 \mathrm{~m}(3.3 \mathrm{ft})$ at the top and $1.2 \mathrm{~m}(3.9 \mathrm{ft})$ at the bottom and along the sides. The activa core is wade up of 247 columns of fuel with six individual fuel elements vertically stacked in each column. Each of the hexagonal fuel elements is 386 (14.2 in.) across flats and 792 -m (31.2-in.) long. The fuel columns are grouped into 37 regions, each containing seven columns, except for 6 regions at the core periphery which contain five columns. The central colunn of fuel elements in each region has three parallel channels through the top reflector and the 


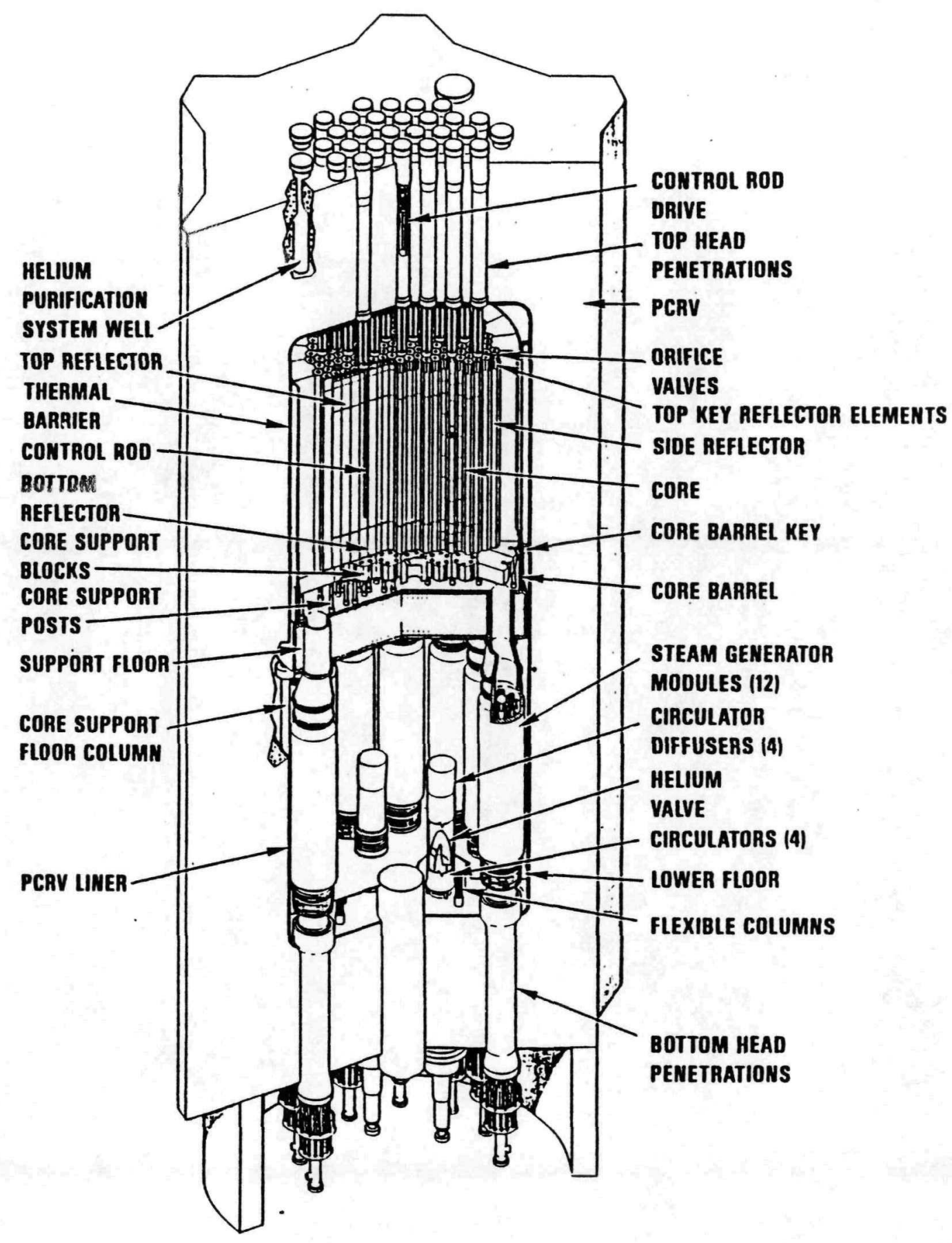

Fig. A-4. FSV reactor general arrangement 
active fuel zones. Two of the channels are for cylindrical metal-clad $\mathrm{B}_{4} \mathrm{C}$ control rods that move as anit. The third channel is available for the insertion of reserve shutdown material.

The fuel is contained in the graphite elements as blended beds of coated fuel particles and coke filler. The fresh fuel materials are high enriched uranium (HEU) and fertile thorium in carbide form. The uranium and thorium carbide particles are coated with layers of pyrocarbon and silicon carbide and bonded into fuel compacts and located in the fuel holes within the hexagonal graphite elements.

Initial criticality was achieved in 1974, and extensive testing was conducted throughout the initial cycle. Subseguent cycles have provided additional measurements.

\section{A.5. HIGH-TEMPERATURE LATTICE TEST REACTOR}

The high-temperature lattice test reactor (HTLTR) was operated at the Batelle Northwest Laboratories (BNWI) as a part of the USAEC General Reactor Technology Program. During 1970 through 1971 an experimental program was conducted to measure the temperature coefficient for HTGRs. This reactor is unique in that it permits operation at an ambient temperature of $1000^{\circ} \mathrm{C}\left(1832^{\circ} \mathrm{F}\right)$ for extended periods of time (several weeks) and to make precise measurements of reactivity worths of sample lattice materials while at temperature.

The HTLTR and its supporting facilities are shown in Fig. A-5. The reactor consists of a $3-m(10-f t)$ cube of graphite enclosed in a carbon steel shell oven which is thermally insulated and gas-tight. The reactor core consists of nuclear grade graphite bars which are stacked, keyed, and doweled together to form a solid unit. The 1.5-m$(5-f t)$-square by $3-\mathrm{m}$ - (10-ft)-long central section is removable to permit loading of different test assemblies. The central test cell of an experimental core can thereby be provided with a flux environment 


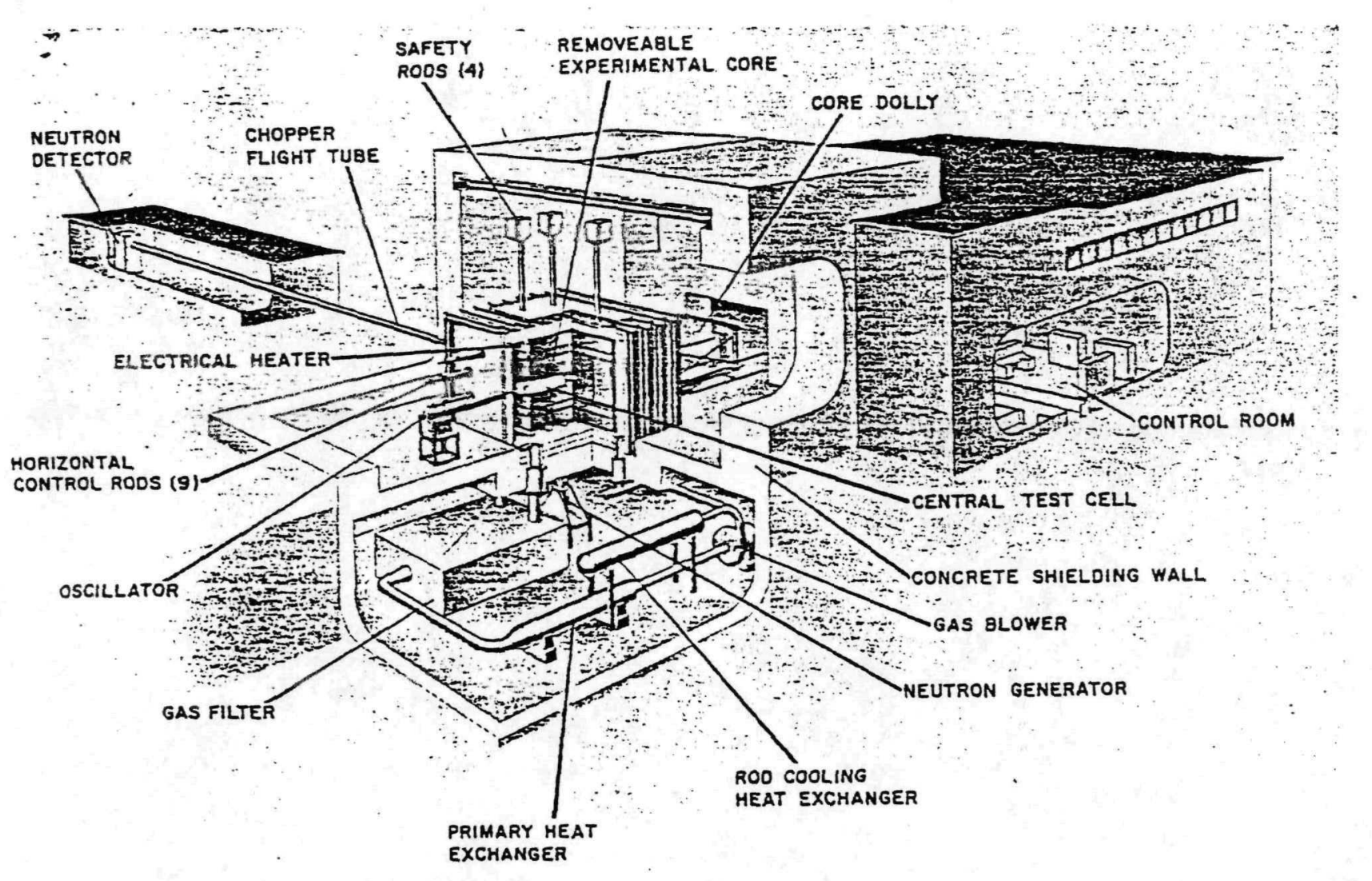

Fig. A-5. Schematic illustration of HTLTR and supporting facilities 
characteristic of its own kind of cells in a critical array. Enriched uranium driver fuel and control rods are located in symetric positions surrounding the test section. The reactor, rated at $2 \mathrm{~kW}$ for nuclear operation, can be heated electrically and operated with average graphite temperatures of up to $1000^{\circ} \mathrm{C}\left(1832^{\circ} \mathrm{F}\right)$.

\section{A.6. ARBEITSGEMEIXSCRMET VERSUCHS-REAKTOR}

The Arbeitsgemeinschaft Versuchs-Reaktor (AVR) nuclear power station in Jilich, which is the oldest operating experimental nuclear power station in the Federal Republic of Germany, is equipped with a pebblebed high-temperature reactor and has been in successful operation for 20 years. The core is designed to operate at a power of $46 \mathrm{MW}(t)$ at an average core power density of $2.6 \mathrm{MW}(t) / \mathrm{m}^{3}$.

The core of the AVR has a diameter of $3 \mathrm{~m}$ (118 in.) and consists of a bed of approximately 100,000 graphite spherical fuel elements (pebbles) which contain the heavy metal in the form of coated particles. The pebbles have a diameter of 60 (2.4 in.). The cylindrical graphite reflector is surrounded by carbon blocks for insulation. A vertical cross section is shown in Fig. A-6. The core contains both HEU and LEU fue1. The LEU fueled pebbles were first added to the core in 1982. Currently, about $25 \%$ of the core consists of LEU fuel (1.e., $50 \%$ of the outer fuel zone).

During reactor operation, fuel elements are removed continuously at the bottom and returned at the top of the core. Burnup is determined for all spheres. Pebbles with full burnup are removed and replaced by fresh elements. During one full power year, the pebble inventory, on the average, is circulated twice.

The side reflector has four equally spaced buttresses which extend into the core, and each contains a vertical channel for a shutdown control rod. 


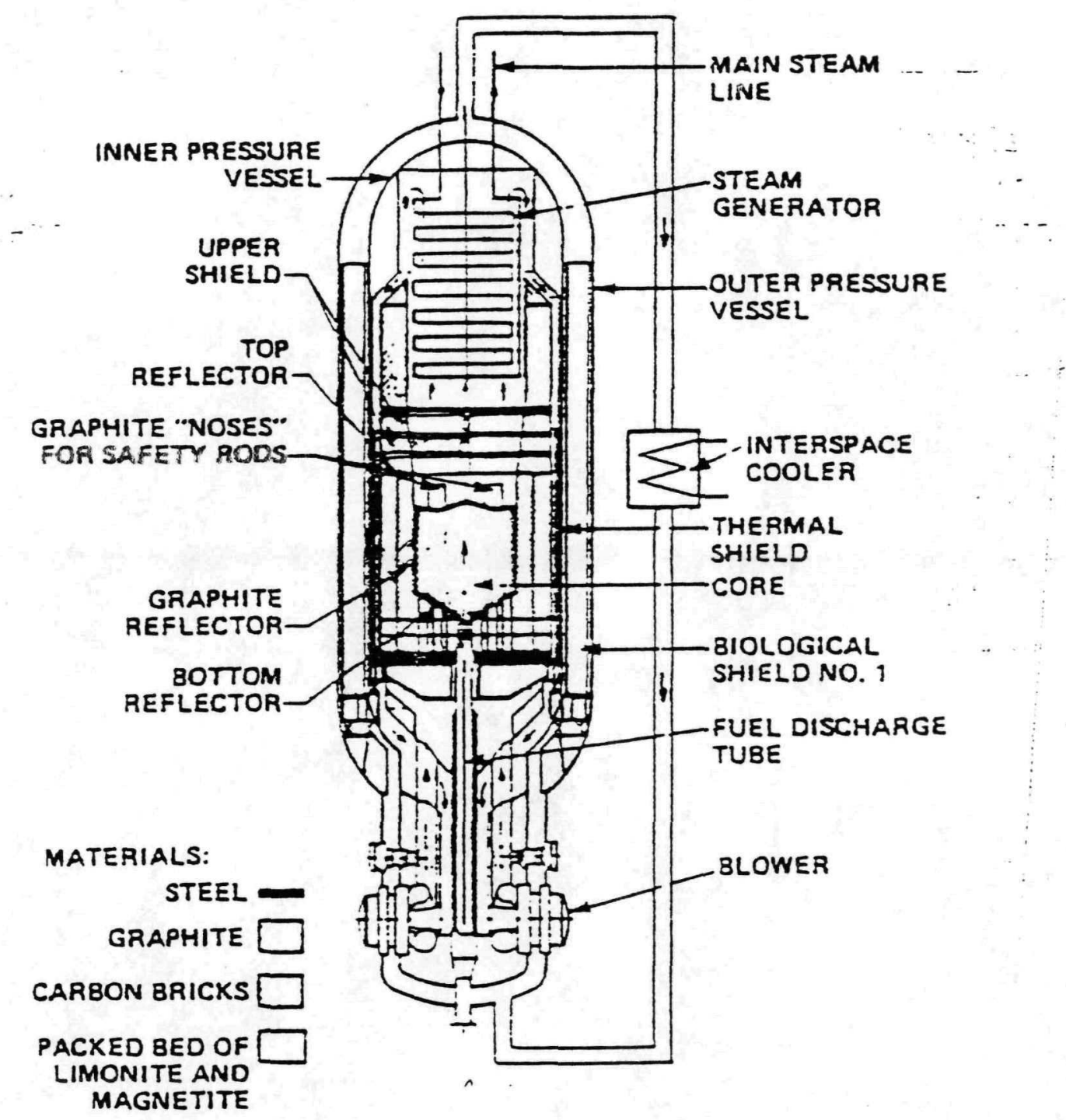

Fig. A-6. Vertical cross section of AVR 


\section{A.7. VERY HIGH-TEMPERATURE REACTOR CRITICAL}

The very high-temperature reactor critical assembly (VHTRC) is operated by JAERI in order to perify the design and safety of the VHTR. Critical caperiments have been conducted since 1985.

The VHTRC assembly is a horizontal split-bed type consisting of two half-machines, one movable and the other fixed (see Fig. A-7). The core and reflector consists of stacks of hexagonal graphite blocks. The fuel elements contain coated fuel particles with enrichments of $2 \%$ to $4 \%$ The core is controlled with cadmium control rods and safety rods.

\section{A.8. CKPS CRITICAI}

\section{[Later]}

\section{A.9. DRAGON REACTOR}

The Dragon reactor was an experimental bellum-cooled, graphitemoderated and reflected high-temperature reactor built and operated in Winfrith, United Kingdom. The reactor was designed to produce a power of $40 \mathrm{MW}(t)$ at an average power density of $14.0 \mathrm{MW}(t) / \mathrm{m}^{3}$.

The core consisted of hexagonal fuel elements which contalned the fuel rods. These rods contained fuel compacts with HEU and thorium fuel dispersed in a graphite matrix. The active core had an equivalent diameter of $1.1 \mathrm{~m}(3.5 \mathrm{ft})$ and wedght of $2.5 \mathrm{~m}(8.3 \mathrm{ft})$. The reactor was controlled by control rods located in the inner radial reflector at a radius of $0.62 \mathrm{~m}(24.4 \mathrm{In}$.$) from the core center (see \mathrm{Fig} . \mathrm{A}-9$ ).

The reactor operated successfully from 1964 through 1975, when it was shut down permanently. 


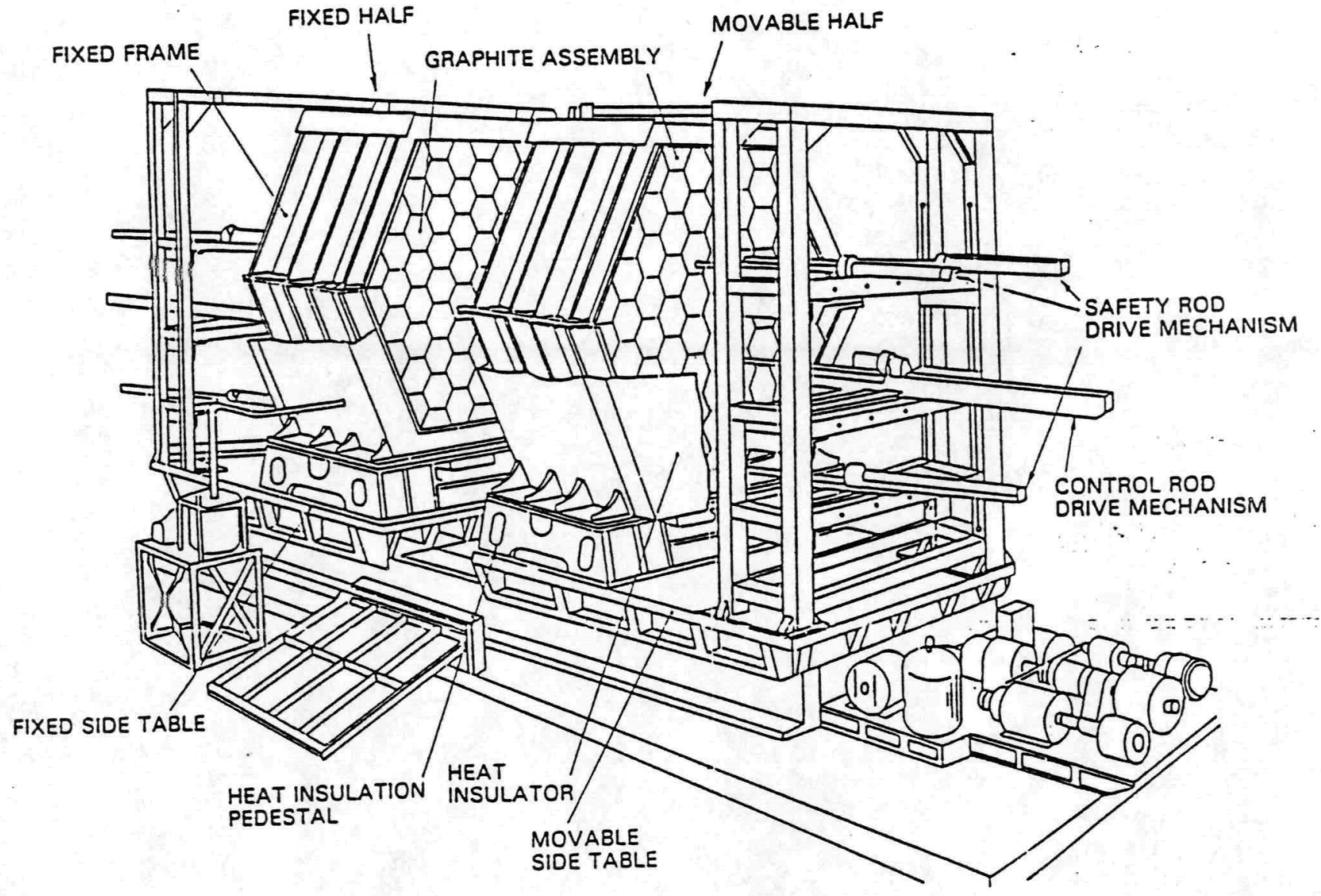

Fig. A-7. Illustrative diagram of the VHTRC facility 
PC $-000280 / 0$

Fig. A-8. [Later] 


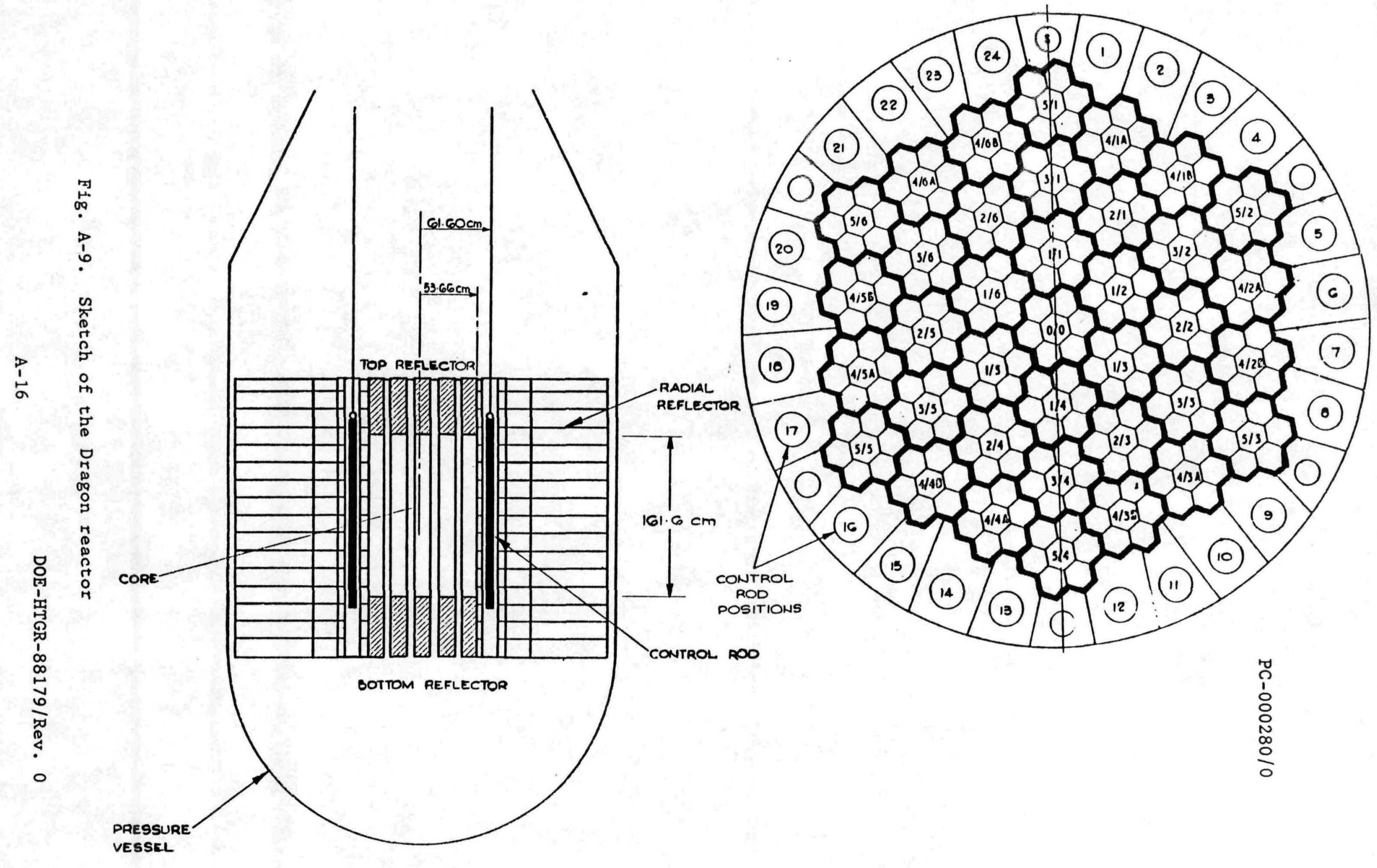




\section{A.10. HIGH-TEMPERATURE REACTOR EXPERIMENT}

The high-temperature reactor experiment (HITREX) zero-power experimental Eacility was located at the Berkeley National Laboratorles (BNL) of the Central Electriciny Generating Board (CEGB) in England. The HITREX program consists of two series: HITREX-1, started in 1971 and completed in 1974, and HITREX-2, a follow-on experimental series that incorporated an integral fuel block design.

HITREX-1 consisted of hexagonal graphite blociss which formed the core of tis reactor. The central region (test zone) of the core is fueled with 3.37 eariched $\mathrm{TO}_{2}$ in a teledial configuration. The driver zone, surrounding the test zone consisted of hexagonal graphite blocks loaded with an asnular-type fuel.

The HITREX-2 reactor experiment, Incorporating a zone of integral block fuel, was built to enable the investigation of HTR core physics to be extended to this fuel type. The core layout is shown in Fig. A-10.

\section{A.11. KRITISCHE ANLAGE HOCHTEMPERATURREAKTOR}

The critical facility Kritische Anlage Hochtemperaturreaktor (KAHTER) established at the KFAs Institut fur Reaktorentwicklung to test, compare, and (if necessary) correct the theoretical models, codes, and data bases, which are used for nuclear layout and safety analysis concerning the HTGR pebble-bed reactor. KAHTER was first critical in sumer 1973. Since then a detalled experimental and theoretical nuclear program has taken place.

The core of the critical facility RAHTER (Fig. A-11) has a diameter of $2.2 \mathrm{~m}$ ( $85 \mathrm{in.})$ and aximum height of $2.8 \mathrm{~m}$ (109 in.). It is reflected on the bottom by $0.24-$ or $0.50-\mathrm{m}-(9.4-$ or $19.7-\mathrm{cm})-t h 1 \mathrm{ck}$ graphite and circumferentially by $0.4-\mathrm{m}$ - (15.7-in.)-thick graphite. A top reflector of graphite with a height of 0.10 to $0.50 \mathrm{~m}$ (3.9 to 


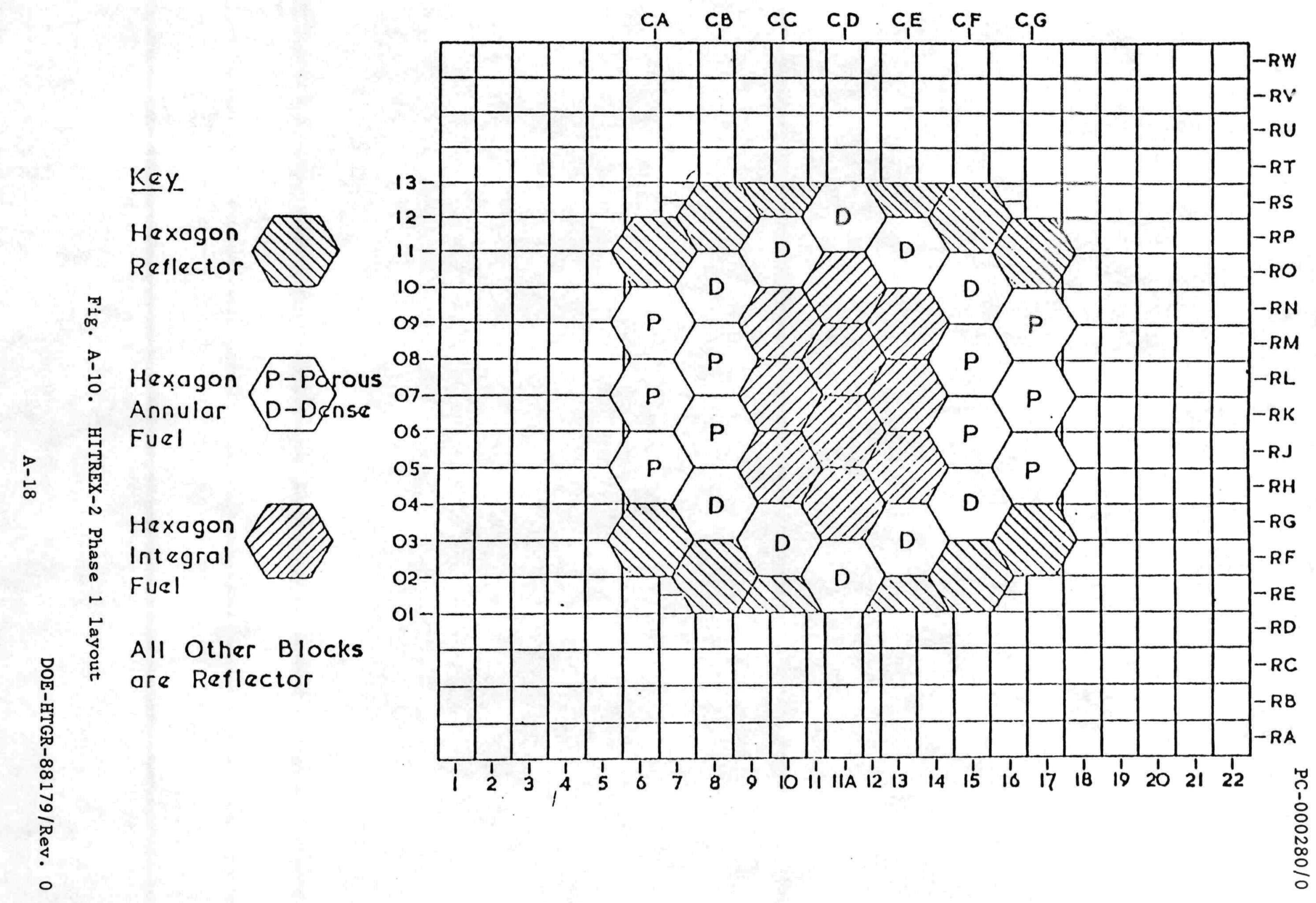




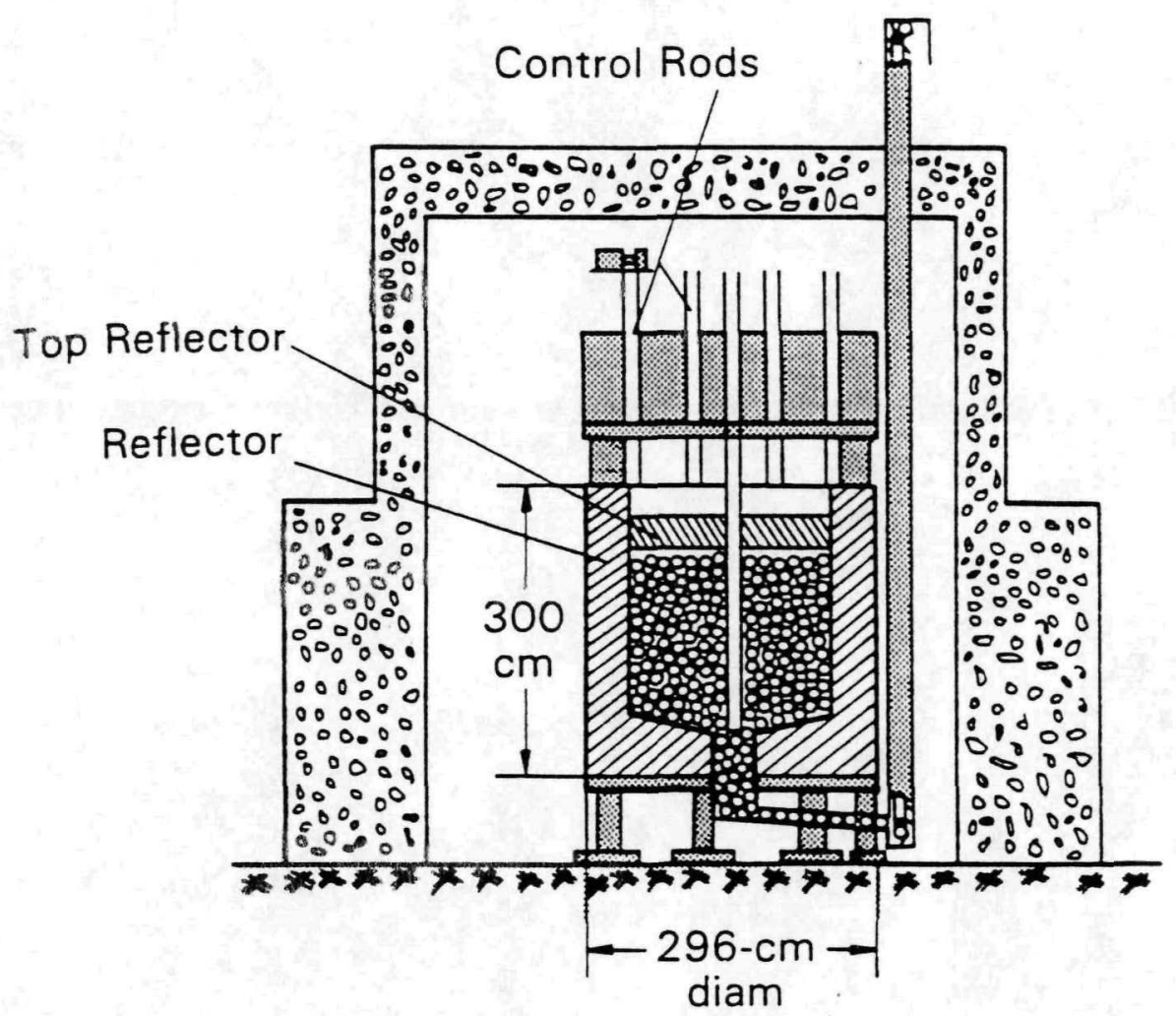

Fig. A-11. Schematic view of the KAHTER facility 
19.7 in.) may be installed. This core can be filled with up to 50,000 pebble-type elements. By mixing fuel elements with graphite pebbles, it is possible to vary the ratio of graphite to heavy metal from 340 up to 1350. Nine control rods (eight in the radial reflector and one central rod) control or shut down the reactor system. Boron carbide was chosen as the neutron-absorbing material in all rods.

\section{A.12. MARIUS}

The MARIUS facility, located in Grenoble, France, consists of a graphite-moderated assembly with an outer reflector, fuel driver region, and a central regon which can be loaded with various test assemblies. The graphite assemblies are stacked with a diameter of $\sim 6.2 \mathrm{~m}(20.3 \mathrm{ft})$ and a length of $\sim 6.0 \mathrm{~m}(19.7 \mathrm{ft})$. Figure A-12 shows a sketch of this assembly and a cross section view. 


\section{A. SKETCH OF FACILITY}

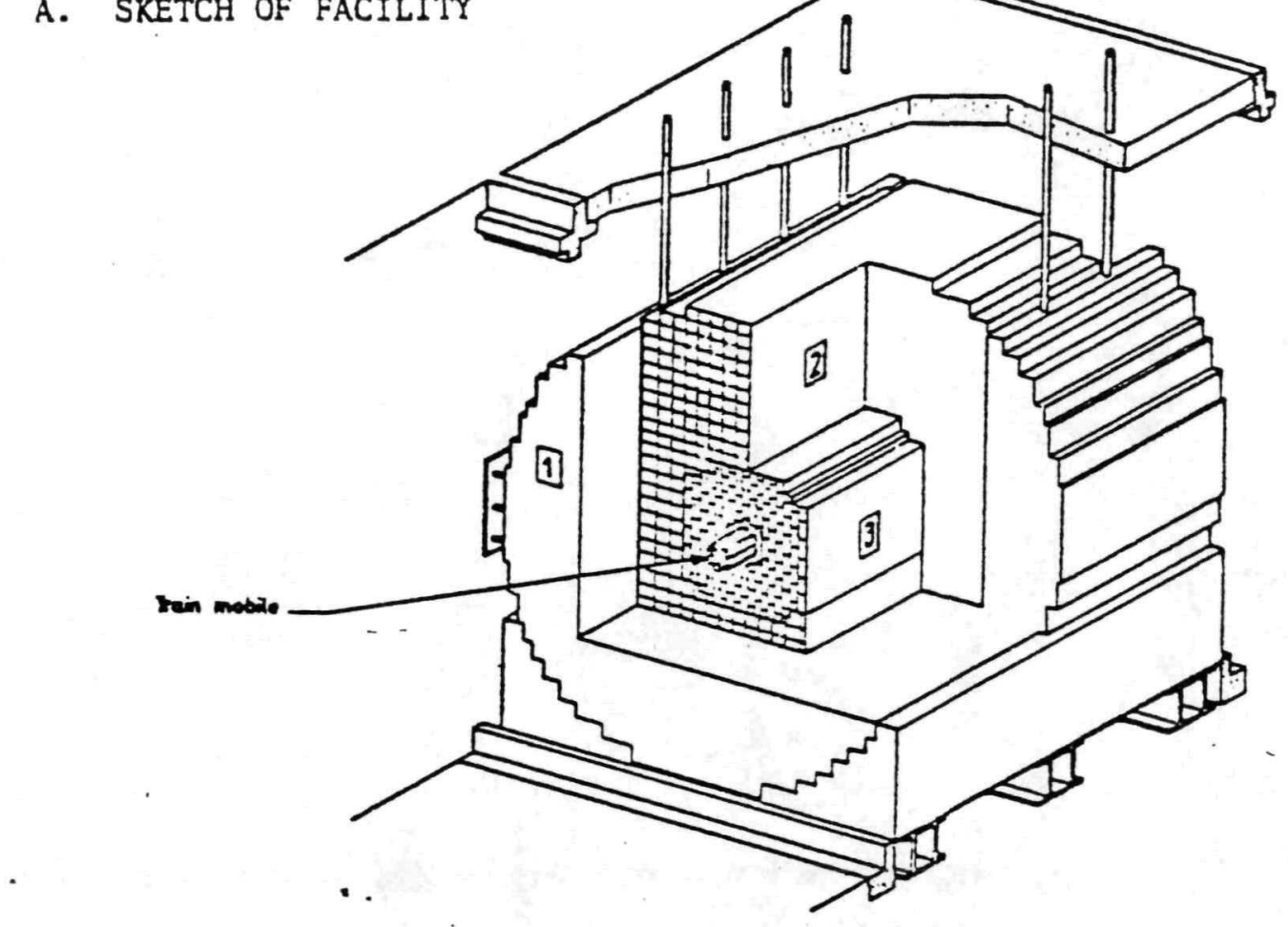

PC $-000280 / 0$

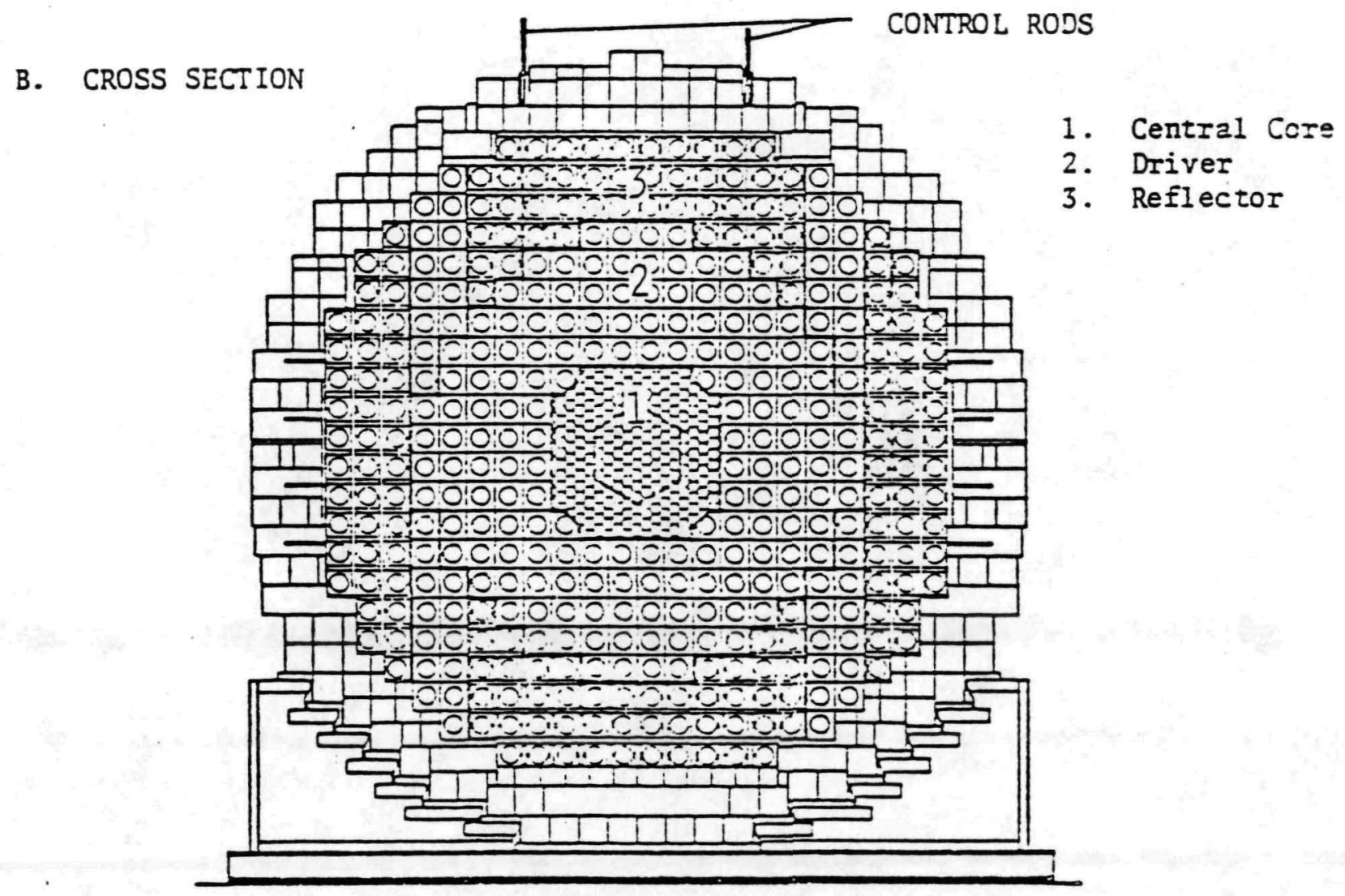

Fig. A-12. MARIUS critical facility 